\title{
The Optimal Tariff in the Presence of Trade-Induced Productivity Gains
}

\author{
Michael Hübler ${ }^{\dagger}$ and Frank Pothen ${ }^{\ddagger}$
}

October 13, 2014

\begin{abstract}
We scrutinize the impact of international productivity gains (technology spillovers), induced by imports and exports, on optimal tariffs with respect to welfare effects. We proceed in three consistent steps. First, we solve a stylized 2x2 trade model of a large open economy and show that (a) productivity gains via exports and imports both reduce the strategically optimal tariff, (b) there exists a certain strength of productivity gains such that the incentive to manipulate the terms of trade strategically vanishes, (c) the welfare gain that can be achieved via a tariff is lower in the presence of productivity gains than in their absence, and (d) these results even hold without power on international markets. Second, we estimate the key model parameters with a panel dataset covering 40 countries, 29 sectors and the years 1995 to 2009 . We find that import-driven productivity gains are stronger than export-driven gains. Third, we extend our model to an 8-region, 18-sector CGE model that we calibrate to the dataset and the estimates of the econometric analysis. We find that the USA's and China's optimal tariffs are reduced by $17 \%$ and Brazil's by $40 \%$ when taking endogenous trade-induced productivity gains into account. The USA are the only model region that gains from European optimal tariffs. Regressions based on the CGE results show that higher import or export intensities as well as higher sector or consumption shares raise the optimal tariff. A sensitivity analysis reveals that higher Armington elasticities substantially reduce the optimal tariff.
\end{abstract}

JEL Classifications: F12, F14, F17, O33, O40

Keywords: international trade, optimal tariff, productivity gains, technology spillovers

\footnotetext{
*We thank Simon Koesler and Alexander Glas for their great help. We gratefully acknowledge financial support by the state of Baden-Württemberg within the programme Strengthening Efficiency and Competitiveness in the European Knowledge Economies (SEEK).

${ }^{\dagger}$ Corresponding author: huebler@iuw.uni-hannover.de, tel: +49-511-762-19569, fax: +49-511-762-2667, Leibniz Universität Hannover, Königsworther Platz 1, 30167 Hanover, Germany.

${ }^{\ddagger}$ ZEW Mannheim, Germany.
} 


\section{Introduction}

Economies do not only benefit from international trade via Ricardian specialization according to their comparative advantages or by exploiting economies of scale. When knowledge and ideas are embodied in traded goods, economic openness will additionally provide access to knowledge stocks abroad (Grossman and Helpman, 1991). Furthermore, openness implies enhanced competition and more efficient production via firm selection (Melitz, 2003). As a consequence, international trade creates a positive externality on trading economies in form of productivity gains.

If, on the contrary, an economy exhibits power on international markets, it can increase domestic welfare by erecting trade barriers and thereby manipulating the terms of trade. Surprisingly, it has hardly been investigated how strategic trade policy is altered in the presence of trade-induced productivity gains, in particular embodied technology spillovers. This paper fills this gap, both qualitatively and quantitatively. The paper hypothesizes that trade-induced productivity gains significantly reduce optimal tariffs and the resulting welfare gains. To examine this hypothesis, the paper sets up and solves a theoretical model; it estimates trade-related productivity gains based on this model econometrically; and it applies the estimates to a computable general equilibrium (CGE) model. It is a main contribution to the literature that the paper integrates these three methodological parts in a monolithic way such that all parts build on the same model and the same dataset.

The theoretical analysis highlights that setting a tariff without taking international productivity spillovers into account will fail to achieve the welfare optimum. It proves that productivity gains through imports and exports reduce the optimal tariff. If spillovers are strong enough compared to a country's market power, they can offset the incentive to abuse that power completely. Unlike in the model by Markusen (1975), power on international markets is not a prerequisite for productivity spillovers to be policy-relevant. The trade-induced productivity increasing externality occurs in the home country so that there is no need to manipulate international prices to internalize it. The theoretical model, however, does not intend to introduce new sophisticated theoretical elements, but to clarify the economic mechanisms at work and to create a basis for the numerical analyses.

Unlike many existing studies, the econometric estimations utilize the same novel dataset as the computational part: the World Input-Output Database (cf. Dietzenbacher et al., 2013) providing bilateral and bisectora 11 production, consumption and trade data for 40 countries and 35 sectors for the years 1995 to 2009. The econometric analysis approves in accordance

\footnotetext{
${ }^{1}$ Trade origins from a specific country as well as a specific sector and flows to another country and another sector.
} 
with the literature (summarized by Saggi, 2002; Keller, 2004) that import- as well as exportrelated productivity gains exist and shows that import-induced productivity gains are larger than export-induced ones.

The focus of this paper is on the numerical model analysis. In this analysis, we illustrate the policy-relevance of our considerations by implementing the theoretical and econometric findings into a CGE model. We find for the USA and China that optimal tariffs are reduced by $17 \%$ and for Brazil that they are reduced by $40 \%$ when taking trade-induced productivity gains into account. Running regressions on the CGE results, we show that higher import or export intensities as well as higher sector or consumption shares significantly raise the optimal tariff and its welfare effects. A sensitivity analysis reveals that the policy results react sensitively to changes in the Armington elasticities that determine substitution possibilities between traded goods and reflect power on international markets. The insights of this paper are recent and policy-relevant, for example, with respect to the transatlantic free trade agreement between the USA and Europe. They provide an argument for the reduction of trade barriers which is sometimes overlooked and which has been quantitatively opaque.

This papers relates to the optimal tariff literature which has a long tradition. Johnson (1954) demonstrates in a two-by-two model that under certain conditions a country will gain from imposing an strategic optimal tariff. Hamilton and Whalley (1983) highlight that in reality tariffs are "some distance from optimal tariffs" and that there is potential for making use of strategic optimal tariffs. They affirm that import price elasticities are crucial for setting optimal tariffs. Referring to the political economy literature, Mayer (1984) notes that "political decisions on tariff rates are reflections of the selfish economic interests of voters, lobbying groups, politicians, or other decision makers in trade policy matters". Gros (1987) suggests (drawing upon Krugman, 1980) that the optimal ad valorem tariff is an increasing function of the economy size and product differentiation. Kennan and Riezman (1988) claim that especially large open economies are able to manipulate the terms of trade in their favor. Brown (1987) argues that an Armington (1969) trade specification creates a strong terms-of-trade effect independent of country size so that even small countries will choose non-zero optimal tariffs. Brown (1987) shows that the terms-of-trade effect will vanish if the elasticity of substitution between imported varieties or imported varieties and the domestically produced variety becomes infinite. Markusen and Wigle (1989) highlight that optimal tariffs will be smaller when the imposing country is smaller, when there are scale economies and free entry or in the presence of international capital mobility. Different to this influential study, we show that optimal tariffs will be smaller in the presence of endogenous trade-induced productivity gains. This aspect is to our knowledge new in the optimal tariff literature. Kennan and Riezman 
(1990) exhibit that members of custom unions can become better off than under free trade by imposing optimal tariffs. Broda et al. (2008) argue that, given power on international markets, "countries set import tariffs nine percentage points higher on inelastically supplied imports relative to those supplied elastically." Their results underline the policy relevance of optimal tariff literature. Ossa (2011) performs a theoretical as well as a numerical multi-region analysis based on GTAP 8 (Global Trade Analysis Project). The regional aggregation used in the following paper is similar to Ossa's, whereas the sectoral aggregation is much more detailed than Ossa's aggregation. This provides new insights on the sectoral level. Without retaliation Ossa finds optimal tariffs averaging around 60 per cent, resulting welfare gains around two per cent and welfare losses for regions abstaining from optimal tariffs around 0.7 per cent. These results highlight the beggar-thy-neighbor character of trade policy. With strategic retaliation, however, welfare gains vanish, and welfare losses of almost three per cent occur throughout all regions. Based on these results, we abstain from an analysis of strategic retaliation, which would be welfare deteriorating for the model regions and which would distract the focus of our analysis from the novel aspect that we introduce: trade-induced international productivity gains.

The paper proceeds as follows: section 2 sets up and analyzes the theoretical framework. Section 3 explains the econometric strategy derived from the theoretical framework and the results. This illuminates the magnitude of the theoretical effects. Section 4 applies the theoretical framework and the estimated parameter values to a computable general equilibrium (CGE) model. This illuminates the policy relevance of the theoretical effects. Section 5 concludes with policy implications.

\section{Theoretical basis}

This section sets up and analyzes our theoretical framework. We draw upon Markusen's (1975) general equilibrium two-by-two trade model in the modified version by Jakob et al. (2013). This algebraic model describes trade policy in the presence of a negative transboundary, environmental externality. The home country wishes to influence foreign country's producers so that their impact on the home country via the transboundary externality is attenuated. The means to influence foreign producers' behavior is manipulating the terms of trade. When the home country imposes a higher tariff on its imports from the foreign country, foreign producers will produce less for the export market so that the externality will be mitigated. The theoretical framework mainly aims at providing a profound basis for the following numerical analyses. It does not intend to introduce a new model type or theory with sophisticated features. 
Different to Markusen (1975) and Jakob et al. (2013), we do not implement a negative environmental externality of trade, but a positive productivity externality of trade. The positive productivity externality occurs in the home country and is associated with imports as well as exports. First, the positive externality can emerge through international technology spillovers. A broad literature stream (summarized by Saggi, 2002; Keller, 2004) has identified imports as a source of international technology spillovers. Imports embody advanced knowledge that can be exploited, and imports are often associated with international enterprises that exchange knowledge between their affiliates. Knowledge can further spill over from foreign affiliates to local firms. Second, the positive externality can emerge through increased competition and firm selection through exporting as described by Melitz (2003)2 2 and the vast literature based on this seminal contribution. In particular, Felbermayr et al. (2013) analyze strategic trade policy in a Melitz model. In their model, the optimal tariff addresses a mark-up distortion, an entry distortion and a terms-of-trade externality. Our work is, however, more general by looking at export- as well as import-related productivity gains and by addressing a technology spillover externality, which creates additional effects. The following subsections set up and solve our basic model.

\subsection{Model setup}

Let us assume a large open endowment economy, called Home, producing two tradable goods, $X$ and $Y$. We do not model the rest of the world and its strategic behavior or reaction explicitly and restrict the analysis to Home's unilateral trade policy. We therefore focus on technology spillovers associated with trade in $X$ and $Y$ that occur in Home. We assume that technology spillovers from Home to the rest of the world have negligible effects on production and trade patterns abroad, because Home is too small a technology source. This implies that Home's policy takes into account what effect trade-induced technology spillovers have within Home, but not what effects they might have in various countries in the rest of the world and how these countries would adjust their production and trade patterns due to spillovers. Taking this into account would create complex, ambiguous interactions, because the effects of technology spillovers vary across countries and because it is an open question whether technology spillovers abroad are beneficial or detrimental for Home. We further assume that goods $X$ and $Y$ are produced by one representative firm per sector. Each representative firm characterizes the behavior of a large number of atomistic firms in the sector. Therefore, firms cannot exploit market power in terms of price setting on national or international markets. We define $p^{0}=\frac{p^{Y}}{p^{X}}$

\footnotetext{
${ }^{2}$ In the Melitz model of heterogeneous firms, trade liberalization induces the exit of low-productivity firms and the expansion of the profits and the market share of high-productivity exporting firms. This reallocation across firms raises overall productivity and welfare.
} 
as the domestic price for good $Y$ relative to good $X$. Defining $X$ as the numeraire with $p^{X}=1$ results in $p^{0}=p^{Y}$.

Home's production pattern depends upon $p^{0}$ and can be characterized by the following concave, decreasing production possibility frontier:

$$
Q^{X}=F\left(Q^{Y}\right), F_{Q^{Y}}<0, F_{Q^{Y} Q^{Y}}<0
$$

$Q$ denotes produced quantities. In general, quantities are measured in constant currency values throughout the paper. $T$ determines the output of $X$ that can be generated when producing a certain quantity of $Y$. One can imagine that the exogenously given quantity of production factors (resources) limits total production of $X$ and $Y$.

Home's consumption pattern also depends upon $p^{0}$ and can be characterized by the following concave, increasing utility function:

$$
U\left(C^{X}, C^{Y}\right), U_{C^{X}}>0, U_{C^{Y}}>0, U_{C^{X} C^{X}}<0, U_{C^{Y} C^{Y}}<0
$$

$C^{X}$ and $C^{Y}$ denote consumed quantities and hence demand.

Home's trade pattern can be described as follows. Let us without loss of generality assume that Home is a net exporter of $X$ and a net importer of $Y$. We assume a balanced trade budget closure so that the following condition holds:

$$
E^{X}=p^{*} M^{Y}
$$

$E$ denotes exports, whereas $M$ denotes imports. International prices are expressed as $p^{*}=\frac{p^{Y *}}{p^{X *}}$. In general $p^{*}$ differs from the domestic price ratio $p^{0}$. Home's terms of trade improve when $p^{*}$ declines. The following expressions characterize the influence of Home's exports and imports and international prices:

$$
p_{M^{Y}}^{*}>0, p_{E^{X}}^{*}>0
$$

A lower index represents a derivative with respect to the corresponding variable throughout the paper. Higher imports into Home raise the world market demand for $Y$ and hence the relative price for $Y$, signified by $p^{*}$. Conversely, higher exports from Home raise the world market supply of $X$ and hence again $p^{*}$.

Following a common theoretical approach that does not focus on dynamic growth paths, but on complex multi-player settings, we project our theoretical considerations onto two periods. The first period signifies today's situation, or in other words, the short-term. The second 
period signifies the long-term until "doom's day". All long-term effects of trade and economic growth are projected onto the second period. Let us therefore introduce a time index $t$ that encompasses two periods $\{1 ; 2\}$. For the sake of simplicity and mathematical tractability, we assume that knowledge spillovers only occur in the first period $t=1$, whereas they are realized in the second period $t=2$. This view takes into account that technology diffusion processes require time. Second-period trade and its growth effects are not relevant for this analysis and hence not explicitly taken into account. Following the literature on trade-induced productivity gains (see section 3 ), we assume that second-period productivity $A^{2}$ proportionately relates to first-period productivity $A^{\cdot 1}$ in each sector in the following fashion:

$$
\begin{aligned}
& A^{X 2}=\left(1+\gamma^{0}+\gamma^{E} \frac{E^{X 1}}{Q^{X 1}}\right) A^{X 1} \\
& A^{Y 2}=\left(1+\gamma^{0}+\gamma^{M} \frac{M^{Y 1}}{Q^{Y 1}}\right) A^{Y 1}
\end{aligned}
$$

$\gamma^{0}$ captures exogenous growth raising productivity of production equally for both sectors, $X$ and $Y$. This corresponds to an proportionate outward shift of the production possibility frontier by the factor $\gamma^{0}$ without sector bias. With regard to exogenous growth, this assumption implies that the choice of the production point (the shares of $X$ and $Y$ production in total production) in the second period equals that of the first period, while quantities in absolute terms are multiplied by $\gamma^{0}$.

The focus of our analysis is on trade-related productivity growth. We assume that traderelated growth adds to exogenous growth and is strictly separable from exogenous growth. Trade-induced productivity gains emerge unexpectedly in the second period. This implies, producers do not anticipate and internalize the productivity gains from trade. Hence, producers' choice of relative $X$ and $Y$ production in any period is not affected by trade-induced productivity gains without policy intervention. To model the unanticipated externality, we assume that productivity gains in period 2 depend on Home's export and import intensity (measured relative to production) in period 1 . We assume that the externality is sector-specific so that a higher export intensity in the $X$ sector expands second-period $X$ production. $\gamma^{E}$ governs the strength of export-induced productivity gains, which are supposed to capture Melitz-type firm selection effects, productivity gains from competition on export markets and possibly technology spillovers through contact with trading partners, although technology spillovers are mainly expected from importing. A higher import intensity expands second-period $Y$ productivity in the analog way. $\gamma^{M}$ governs the strength of import-induced productivity gains, which are supposed to capture technology spillovers and productivity gains from competition on import markets. In this typical two-by-two trade setting with homogeneous products, each sector is 
either a net exporter (here $X$ ) or a net importer (here $Y$ ). This simplification will be relaxed in the econometric estimation and in the numerical model calibration in order to fit theory to data. Formally, we write sectoral second-period productivity $A^{X 2}$ and $A^{Y 2}$ as a function of first-period export intensity $\frac{E^{X 1}}{Q^{X 1}}$ and import intensity $\frac{M^{Y 1}}{Q^{Y 1}}$. We employ the intensity form to make spillovers independent of sector size.

Second-period output of both sectors follows from profit maximization given the new productivity levels. We assume that sectoral productivity growth results in sectoral output growth. Nevertheless, sectoral output can expand more or less than proportionately to productivity, because in a general equilibrium, sectoral shifts of production and consumption can occur. As a result, second-period output relates to first-period output in the following fashion:

$$
\begin{aligned}
& Q^{X 2}=\underbrace{\left(1+\gamma^{0}+\gamma^{E} \frac{E^{X 1}}{Q^{X 1}}\right)}_{T^{X 2}} S^{X 2} Q^{X 1} \\
& Q^{Y 2}=\underbrace{\left(1+\gamma^{0}+\gamma^{M} \frac{M^{Y 1}}{Q^{Y 1}}\right)}_{T^{Y 2}} S^{Y 2} Q^{Y 1}
\end{aligned}
$$

$T^{\cdot 2} \geq 1$ denotes the technique or productivity effect for each sector as defied by Equation (5). $T^{\cdot 2}=1$ implies the absence of productivity gains. $S^{\cdot 2} \geq 0$ denotes the sectoral composition effect for each sector: in a general equilibrium, consumption and production points can shift additionally to the sectoral expansion driven by the sector-specific technique effect. In general, the composition effect can strengthen or weaken the technique effect. Nonetheless, we assume that the composition effect does not countervail the technique effect in such a way that production shifts overall away from a sector that gains in terms of productivity relative to the other sector. This means, we assume $T^{X 2} S^{X 2}>T^{Y 2} S^{Y 2}$ if $T^{X 2}>T^{Y 2}$. As a consequence, productivity growth in a specific sector will always raise the output of this sector compared to the previous period. This assumption is necessary for obtaining clear-cut theoretical results and follows economic intuition. $S^{2}=1$ implies a neutral composition effect.

\subsection{Closed-form solution}

We are now able to phrase and solve Home's two-period utility maximization problem:

$$
\max _{\left\{Q^{Y 1}, Q^{Y 2}, M^{Y 1}, M^{Y 2}, E^{X 1}, E^{X 2}\right\}} W, \quad W=U^{1}+\rho U^{2}
$$

This formulation allows for discounting second-period utility with a factor $0<\rho \leq 1$, where a lower factor implies a lower value attributed to future utility. Discounting the future reduces the importance of technology spillovers from today's point of view without affecting the qualitative 
validity of our analysis. We assume that there is no change in consumer preferences so that the second-period utility function equals the first-period function.

In order to solve the model, we insert Equations (1) to (4) and (6). We impose a balanced budget condition given by (3) on first-period trade. The total output of each good is fully absorbed. We drop the time index, assuming that all variables refer to period 1. Using (3), we can write the international price ratio $p^{*}$ as a function of $M^{Y}$. Note that we only look at first-period trade like in a static one-period trade-model. By assumption, no induced spillovers occur in the second period, which represents the long-term and does not have a subsequent period. Therefore, the second period reverts to the standard case of the optimal tariff model, and we refrain from displaying Home's optimal trade pattern in the second period to focus our analysis on the spillover-related effects in the first period. As discussed previously, sectoral shifts can strengthen or weaken the output augmenting effect of productivity gains. Their effect is in this sense ambiguous, but per assumption weaker than the effect of productivity on output. Therefore, let us for the sake of mathematical clarity for the moment assume $S^{\cdot 2}=1$, i.e. a neutral composition effect absent any sectoral shifts besides the productivity effect captured by $T^{\cdot 2}$. We will again relax this assumption and allow for any sectoral shifts in our computable general equilibrium in section 4 .

Based on these considerations, we obtain the following maximization problem with firstperiod $Y$ production and first-period imports $M$ as the only control variables 3

$$
\begin{array}{r}
\max _{\left\{Q^{Y}, M^{Y}\right\}} W, \quad W=U\left[F\left(Q^{Y}\right)-M^{Y} p^{*}\left(M^{Y}\right), Q^{Y}+M^{Y}\right] \\
+\rho U\left[\left(1+\gamma^{0}\right) F\left(Q^{Y}\right)+\gamma^{E} M^{Y} p^{*}\left(M^{Y}\right),\left(1+\gamma^{0}\right) Q^{Y}+\gamma^{M} M^{Y}\right]
\end{array}
$$

By executing $\frac{\partial W}{\partial Q^{Y}}=0$ and $\frac{\partial W}{\partial M^{Y}}=0$, we obtain the first-order conditions:

$$
\begin{array}{r}
{\left[1+\rho\left(1+\gamma^{0}\right)\right] U_{C^{Y}}+\left[1+\rho\left(1+\gamma^{0}\right)\right] F_{Q^{Y}} U_{C^{X}}=0} \\
\left(1+\rho \gamma^{M}\right) U_{C^{Y}}-\left(1-\rho \gamma^{E}\right)\left(p^{*}+M^{Y} p_{M^{Y}}^{*}\right) U_{C^{X}}=0
\end{array}
$$

A lower index indicates a first derivative with respect to this variable. We obtain the standard result that a consumer maximizes utility when the ratio of marginal utilities (the marginal rate of substitution) equals the consumer price ratio $q^{0}$ :

$$
q^{0}=\frac{q^{Y}}{q^{X}}=\frac{U_{C_{Y}}}{U_{C_{X}}}
$$

\footnotetext{
${ }^{3}$ Note that the trade- induced productivity gains, $\gamma^{E} M^{Y} \cdot p^{*}\left(M^{Y}\right)$ in the $X$-sector and $\gamma^{M} M^{Y}$ in the $Y$ sector, are independent of first-period production quantities $Q ; Q$ cancels out in the trade-induced terms in Equations (6). Productivity gains solely depend on first-period import and export quantities and the related strengths of productivity gains (spillovers).
} 
We also obtain the standard result that producers earn maximum profits when the ratio of marginal productivities (the technical rate of substitution) equals the negative producer price ratio:

$$
p^{0}=-F_{Q^{Y}}
$$

Rearranging (9) and (10) and inserting (11) and (12) yields:

$$
\begin{aligned}
& q^{0}=p^{0} \\
& q^{0}=(p^{*}+\underbrace{M^{Y} \cdot p_{M^{Y}}^{*}}_{\theta^{\text {strat }}}) \cdot \underbrace{\frac{1-\rho \gamma^{E}}{1+\rho \gamma^{M}}}_{\theta^{\text {prod }}}
\end{aligned}
$$

$p^{0}$ and $q^{0}$ signify first-period prices that take into account second-period outcomes in form of shadow prices. The first equation simply affirms that in the optimum, Home's consumer price equals the producer price. This means, production is unaffected by the existence of tradeinduced productivity gains as specified in Equations (5). The second equation affirms that the optimal tariff drives a wedge between the international price and Home's consumer price. This price wedge can be generated via an import tariff and hence creates an incentive for trade policy intervention. $\theta^{\text {strat }}$ is the well-known strategic term: by imposing a tariff at the rate $\theta^{\text {strat }}=M^{Y} \cdot p_{M^{Y}}^{*}$ in addition to the international price, Home optimally exploits its power on international markets 4 A higher $p_{M^{Y}}^{*}$ implies a stronger reaction of the world market price to changes in Home's imports (and exports). As a consequence, Home's optimal tariff rises in order to exploit the market power increasing in $p_{M^{Y}}^{*}$. Clearly, higher discounting, represented by a lower factor $\rho$, reduces the importance of future productivity gains and hence reduces the price wedge. As a result, higher discounting of the future decreases the incentive for trade policy today.

Proposition 1. In the presence of trade-induced productivity gains, there is an incentive to expand trade even without market power on international markets (when the home country is a small open economy). The potential for expanding trade with the aim to exploit trade-induced productivity gains increases in international market power.

Proof. Consider Equation (14) for a small open economy. Without market power on international markets, $p_{M^{Y}}^{*}$ is zero. Hence, the possibility to manipulate the terms of trade $\left(\theta^{\text {strat }}\right)$ vanishes. The incentive to internalize the productivity effect of trade is nevertheless present, represented by the last term $\left(\theta^{\text {prod }}\right)$. Home attempts to export and import more in

\footnotetext{
${ }^{4}$ The import-dependency of the international price creates a term that is typical for a maximization problem with monopoly power, in this case $M^{Y} p^{*}\left(M^{Y}\right)$ in Equation (8).
} 
order to exploit the trade-induced productivity gains (technology spillovers) that occur within its boundaries. If international prices stay constant and cannot be influenced by Home, Home can nevertheless influence domestic prices relative to the constant international prices. This mechanism differs from Markusen (1975), where the environmental externality occurs abroad and Home requires market power to mitigate the environmental externality in the foreign country by influencing international prices. Hence, in Markusen's model, it is necessary that the home country is a large open economy. In our model, on the contrary, the externality occurs within the home country so that the ability to internalize it does not depend on power on international markets. This result also differs from Brown (1987), where no externality is taken into account so that the terms-of-trade effect will vanish, when traded commodities become perfectly substitutable, i.e. when market power disappears.

Nevertheless, the potential for expanding the externality in absolute terms increases in power on international markets. This can easily be seen in Equation (14). The productivityrelated term $\left(\theta^{\text {strat }}\right)$ reduces any given price wedge in relative terms, i.e. by a factor $\theta^{\text {prod }}<1$. In absolute terms, the effect depends upon the magnitude of $p^{*}+\underbrace{M^{Y} \cdot p_{M^{Y}}^{*}}_{\theta^{\text {strat }}}$. Since $p_{M^{Y}}^{*}$ rises in Home's market power, $\theta^{\text {prod's }}$ s absolute effect also rises in Home's market power. The intuition is that with higher market power, Home has a higher potential for boosting trade by manipulating international prices so that foreign producers intend to enhance trade with Home.

Proposition 2. Productivity gains through imports and exports reduce the optimal tariff that manipulates the terms of trade in favor of a large open economy.

Proof. In Equation (14), $\theta^{\text {strat }}$ attenuates the price for $Y$ imports and elevates the price for $X$ exports relative to each other. This improves the terms of trade in Home's favor but hampers trade in absolute volumes. Stronger productivity gains via exports, expressed by $\gamma^{E}$, or stronger productivity gains via imports, expressed by $\gamma^{M}$, both contradict the effect of $\theta^{\text {strat }}$. This converse effect of productivity gains from trade on the terms of trade is summarized by $\theta^{\text {prod }}$. $\theta^{\text {prod }}<1$ has the form of an ad-valorem subsidy that multiplies the world market price plus the strategic tariff by a factor smaller than one. The intuition is simple: the strategic term improves the international price in Home's favor, but diminishes import and export volumes. Home, on the contrary, attempts to expand import and export volumes in the presence of productivity gains in order to better exploit them.

Proposition 3. For every world market price, there exists a certain strength of productivity gains through imports and exports such that the incentive to manipulate the terms of trade vanishes. 
Proof. Solving Equation (14) in the form $p^{*}=q^{0}=\left(p^{*}+M^{Y} p_{M^{Y}}^{*}\right) \frac{1-\rho \gamma^{E}}{1+\rho \gamma^{M}}$ yields:

$$
\left(\gamma^{M}-\gamma^{E}\right) \rho p^{*}=\left(1-\rho \gamma^{E}\right) M^{Y} p_{M^{Y}}^{*}
$$

If this condition is fulfilled, there will be no difference between the original world market price $p^{*}$ and the one manipulated via Home's optimal tariff. The incentive for beggar-thy-neighbor policies is perfectly offset by the incentive to internalize the productivity spillovers.

Proposition 4. The welfare gain for a large open economy achieved via a given tariff rate is lower in the presence of productivity gains through imports and exports than in their absence.

Proof. More potent market power expressed by a higher $p_{M^{Y}}^{*}$, i.e. a stronger impact of Home's imports on international prices, magnifies the potential for welfare gains through the manipulation of international prices. In Equation (8), a reduction in imports $M^{Y}$ reduces consumption $C^{Y}$, which is detrimental for Home, and simultaneously reduces exports valued by international prices $M^{Y} \cdot p^{*}\left(M^{Y}\right)$, which raises consumption $C^{X}$, which is beneficial. The more potent Home's market power is, the stronger the latter beneficial effect is. As a consequence, the welfare gain that can be achieved by compressing imports is higher under more potent market power. It is obvious in Equation (14) that the productivity gain factor $\theta^{\text {prod }}$ reduces $p_{M^{Y}}^{*}$ and hence the effective market power and thus counteracts the use of strategic tariffs. This in turn attenuates the welfare gain generated by a tariff (the optimal tariff or any other tariff).

The following Section 3 finds evidence for the existence of the productivity gains driving the propositions. Section 4 validates these propositions in a more complex numerical model.

\section{Econometric estimation}

This section estimates the coefficients governing the strength of import- and export-driven productivity gains. Our econometric analysis builds upon a vast literature stream on trade-related international productivity (technology) spillovers as summarized by Saggi (2002), Keller (2004) and Havranek and Irsova (2011) (cf. Coe and Helpman, 1995, and Coe et al., 1997, for seminal papers on North-South productivity spillovers). Although the results of this literature are diverse and ambiguous, the bottom-line is that trade-induced (and more significantly foreign direct investment-induced) international productivity gains do exist. Different to these studies, we contrast import-induced with export-induced productivity gains. Our search for export-induced productivity gains follows the literature that seeks for Melitz (2003) type productivity gains via firm selection. Girma et al. (2004), for example, find for manufacturing 
firms in the United Kingdom that exporters are initially more productive than other firms and additionally become more productive through exporting. It is the contribution of our econometric analysis to compare import- and export-related productivity gains at the country and sector level within a large global dataset. Our econometric analysis itself is, however, mainly an intermediate step that proves the validity of the theoretical model (of section 2) and provides the parameter values for the numerical implementation (in section 4). We abstain from including control variables (besides fixed-effects) because we make the estimations as consistent as possible with the numerical model implementation described in the following section. The numerical implementation does not allow us to include econometric control variables because of model and data restrictions. An extended econometric analysis is therefore beyond the scope of this model-based analysis. Consequently, direct policy inference from our econometric analysis requires some caution and a careful interpretation in the context of the existing literature. The following subsections derive the econometric estimation from the theoretical model and interpret the estimation results.

\subsection{Model setup}

This subsection derives the econometric model from the framework set up in the previous section. Equations (6) implicitly assume that output expands while total input stays constant. Now we let input $Z$, which captures all inputs of production factors as well as intermediate goods, enter the equation explicitly. Furthermore, let us generalize the model to $s$ sectors. In order to fit the model to data, the assumption that each sector produces a homogeneous good which is either imported or exported is dropped. Instead, we take into account that in reality products of sector $s$ can be imported and exported simultaneously. This requires the existence of varieties of each good produced in different countries. For this purpose, we introduce a region index $r$ describing a number of countries. Imports are an aggregate of intermediate goods from all countries available in the dataset. Exports, on the contrary, encompass only the specific good that a sector produces and are in general exported to all countries available in the dataset. In each sector, imports and exports create sector-specific productivity gains. In addition, let $t$ denote time, or more specifically, a year. Let us abstain from discounting and from sectoral shifts in the econometric model, because the available data do not allow us to take these aspects into account. Then, the sectorally and regionally generalized combination of Equations (6) results in the following equation for each country and sector:

$$
\frac{Q^{r s t+1}}{Z^{r s t+1}}=\left(1+\gamma^{0 r}+\gamma^{M} \frac{M^{r s t}}{Q^{r s t}}+\gamma^{E} \frac{E^{r s t}}{Q^{r s t}}\right) \frac{Q^{r s t}}{Z^{r s t}}
$$


The growth factor $\gamma^{0 r}$ is region-specific and to be estimated. The trade-related growth factors $\gamma^{M}$ and $\gamma^{E}$ are assumed to be identical in all sectors and regions and also to be estimated. $\frac{Q^{r s t}}{Z^{r s t}}$ can be interpreted as total factor productivity (TFP) of sector $s$ in region $r$ in year $t$. It is computed from the data. Neglecting possible sectoral composition effects $\left(S^{2}=1\right)$, we treat TFP as a measure for $A$ in Equations $(5) \cdot \frac{M^{r s t}}{Q^{r s t}}$ and $\frac{E^{r s t}}{Q^{r s t}}$ are given by the data. Setting $Z^{r s t+1}=Z^{r s t}$ and multiplying by $Z^{r s t}$ on both sides leads back to Equations (6) leaving aside sectoral shifts. This means, the above equation describes total factor productivity growth. It describes the growth rate of $\frac{Q^{r s t+1}}{Z^{r s t+1}}$ and can therefore be rewritten in $d l o g$ form (differences of natural logarithms). $\gamma^{0 r}$ represents country fixed-effects. Adding an error term $\epsilon^{r s t}$ that captures deviations not explained by the model yields:

$$
d \log \left(\frac{Q^{r s t+1}}{Z^{r s t+1}}\right)=\gamma^{0 r}+\gamma^{M} \frac{M^{r s t}}{Q^{r s t}}+\gamma^{E} \frac{E^{r s t}}{Q^{r s t}}+\epsilon^{r s t}
$$

We estimate this equation using the novel World Input Output Database (WIOD) 5 panel data for 40 countrie: 6 , 29 sectort 7 and the years 1995 to 2009 . It is to our knowledge the first database providing bilateral and bisectoral input-output relations and various socio-economic and environmental indicators for a sequence of years within one consistent dataset. Though, one critique of the WIOD data is that the bilateral trade structure does not stem from original, new data, but has been computed based on fixed trade shares.

The growth of total factor productivity is computed with the help of the production function defined by Equation (19) in the Appendix. The equation depicts the constant elasticity of substitution (CES) nesting structure that will be used in the numerical model. It is assumed that technical progress only affects total factor productivity, while optimal input shares of factors remain constant. Inputs of labor and energy, measured in physical units (million hours

\footnotetext{
${ }^{5}$ The WIOD project has been funded by the European Commission, Directorate General Research, as part of the $7^{\text {th }}$ Framework Programme, Theme 8: Socio-Economic Sciences and Humanities. WIOD has been available for the public since April 2012. See Timmer, M.P. (2012, ed.), The World Input-Output Database (WIOD): Contents, Sources and Methods. http://www.wiod.org/database/.

${ }^{6}$ Australia (ROW), Austria (EUR), Belgium (EUR), Canada (ROW), Czech Republic (EUR), Denmark (EUR), Estonia (EUR), Finland (EUR), France (EUR), Germany (EUR), Greece (EUR), Hungary (EUR), Ireland (EUR), Italy (EUR), Japan (EAS), Luxembourg (EUR), Mexico (ROW), Netherlands (EUR), Poland (EUR), Portugal, Slovak Republic (EUR), South Korea (EAS), Spain (EUR), Sweden (EUR), Turkey (ROW), United Kingdom (EUR), United States of America (USA), Bulgaria (EUR), Brazil (BRA), China (CHN), Cypress (EUR), India (IND), Indonesia (ROW), Latvia (EUR), Lithuania (EUR), Malta (EUR), Romania (EUR), Russia (RUS), Slovenia (EUR), Taiwan (EAS) (for region codes like ROW and explanations see section 3.2 and Table 2).

${ }^{7}$ Agriculture, Hunting, Forestry and Fishing; Mining and Quarrying; Food, Beverages and Tobacco; Textiles and Textile Products; Wood and Products of Wood and Cork; Pulp, Paper, Printing and Publishing; Chemicals and Chemical Products; Rubber and Plastics; Other Non-Metallic Mineral; Basic Metals and Fabricated Metal; Machinery, Nec; Electrical and Optical Equipment; Transport Equipment; Manufacturing, Nec, Recycling; Electricity, Gas and Water Supply; Construction; Wholesale Trade and Commission Trade, Except of Motor Vehicles and Motorcycles; Retail Trade, Except of Motor Vehicles and Motorcycles; Repair of Household Goods; Hotels and Restaurants; Inland Transport; Water Transport; Air Transport; Other Supporting and Auxiliary Transport Activities; Activities of Travel Agencies; Post and Telecommunications; Financial Intermediation; Real Estate Activities; Renting of M\&Eq and Other Business Activities; Health and Social Work; Other Community, Social and Personal Services. 6 WIOD sectors with missing data are left out.
} 
worked, Terajoule), are also taken from the WIOD database. All quantities appearing in the estimation are measured in 1995 US-\$. Elasticities of substitution are taken from Koesler and Schymura (2014). They estimate the elasticities with the help of the WIOD data in a non-linear fashion. Hence, we utilize consistent data and parameter values throughout the econometric and numerical modeling analyses.

\subsection{Estimation results}

This subsection discusses the estimation results reported in Table 1. We always report heteroscedasticity robust standard errors that cluster at the country-level. The estimated importrelated coefficient $\gamma^{M}$ can be economically interpreted in the following way: suppose the exogenous growth rate of a country is 0.02 per year and the import intensity of a specific sector in this country rises from 0.3 to 0.4 , i.e. by 0.1 . As a result, the annual productivity growth rate will increase from 0.02 to 0.02359 . The same interpretation applies to the export-related coefficient, albeit the magnitude of this effect is less than half the import-related effect.

The regressions include 40 country-specific fixed effects. Anticipating the regional structure of our modeling exercise in the following section, we summarize the 40 country-specific results in form of eight region-specific results. To this end, we aggregate the country-specific growth rates by computing GDP-weighted averages (for the country-region matching see footnote 5). Table 2 depicts the eight model regions and the corresponding estimated aggregate, exogenous annual total factor productivity growth rates. The results highlight three aspects:

\begin{tabular}{|c|c|c|}
\hline \multicolumn{3}{|c|}{$\begin{array}{l}\text { Annual growth rate of total factor productivity } \\
\qquad d \log \left(\frac{Q^{r s t+1}}{Z^{r s t+1}}\right)\end{array}$} \\
\hline Import intensity $\frac{M^{r s t}}{Q^{r s t}}$ & $\gamma^{M}=0.0359^{* * *}$ & $(0.0137)$ \\
\hline Export intensity $\frac{E^{r s t}}{Q^{r s t}}$ & $\gamma^{E}=0.0160^{* *}$ & $(0.0078)$ \\
\hline$F$ & 19.44 & $(0.0000)$ \\
\hline$R^{2}$ & 0.0380 & \\
\hline Number of observ. & 15,678 & \\
\hline
\end{tabular}

Table 1: Panel estimation for 40 countries, 29 sectors and 15 years including country-specific fixed-effects.

Result 1. The existence of import- and export-driven productivity gains (technology spillovers) 
Region-specific exogenous annual growth rate of total factor productivity $\gamma^{0 r}$

\begin{tabular}{lll}
\hline & $E U R$ & 0.005 \\
European Union & United States of America & 0.008 \\
Russia & $R U S$ & 0.014 \\
Brazil & $B R A$ & 0.000 \\
India & $I N D$ & 0.017 \\
China & $C H N$ & 0.030 \\
East Asia & $E A S$ & 0.009 \\
Rest of the World & $R O W$ & 0.009 \\
& & \\
\hline
\end{tabular}

Table 2: Aggregated country-specific fixed-effects taken from the panel estimation.

presumed in our theoretical framework is confirmed by the data.

Both, the coefficients of import intensity and export intensity, are statistically significant and positive. This implies that importing and exporting are associated with a positive externality that raises total factor productivity.

Result 2. The strength of trade-related productivity gains is asymmetric: imports entail higher productivity gains than exports.

This result is in accordance with the econometric literature (referred to in the introduction to this section) which in most cases focuses on import- (or FDI-) induced technology spillovers. Consequently, fostering imports will entail higher productivity gains than fostering exports.

Result 3. Taking endogenous trade-induced productivity gains into account, diminishes the strategically optimal international price ratio by about five per cent.

According to (14), the productivity gain factor that diminishes the strategically optimal international price ratio can be expressed as $\theta^{\text {prod }}=\frac{1-\rho \gamma^{E}}{1+\rho \gamma^{M}}$. Assuming $\rho=1$ in order not to influence the result by discounting and inserting the estimations of $\gamma^{E}$ and $\gamma^{M}$ reported in Table 1 yields the factor $\theta^{\text {prod }} \approx 0.95$. Using the delta method, we find that this factor is statistically highly significant. The resulting 95 percent confidence interval is [0.93; 0.97].

In accordance with the literature, our results confirm the existence of positive trade-induced technology spillovers, however, without detecting tremendous effects. Whereas the literature on technology spillovers focuses on imports, we also take exports into account in terms of firm selection and increased competition and find a positive significant effect. More specifically, Hübler and Keller (2009) regress energy intensities of 60 developing countries between 1975 
and 2004 in $d \log$ form on import intensity as in our specification. They find a negative, yet insignificant coefficient of -0.017 for import intensity (in regression B1, which is most similar to our estimation). This result comes close to the coefficient of 0.016 for total factor productivity (the inverse of factor intensity) that we find for export intensity. The coefficient for import intensity is more than twice the coefficient for export intensity in our results. Hübler and Keller (2009), however, utilize energy instead of labor intensity, they do not use sectoral data, they include further regressors, and their results are neither robust across specifications nor significant.

\section{Numerical simulation}

This section implements the growth mechanism that has been theoretically and econometrically studied in the previous sections int the WIOD CGE (World Input Output Database Computable General Equilibrium) model. It particularly addresses the propositions derived in section 2. The results provide numerical evidence and underline the policy-relevance of trade-induced productivity gains.

Our trade analysis is related to numerical studies of trade liberalization as critically reviewed by Ackerman and Gallagher (2008). The authors conclude that the gains from free trade have a small magnitude, which is in line with our results. Ackerman and Gallagher highlight the crucial role of Armington (1969) elasticities, which we will also address in our robustness checks. This literature strand does not take international productivity spillovers into account, though. International productivity spillovers are considered by some studies in the field of development economics. Diao et al. (2005), for example, build a general equilibrium model in which trade-related international technology spillovers enhance economic growth. They calibrate their model to the Thai economy. They demonstrate that protectionism slows down economic growth. Shock trade liberalization creates a strong short-term stimulus, but a smaller long-term stimulus. More recently, the model-based assessment of international climate policy has emphasized the possible role of international technology spillovers in reducing carbon mitigation costs (e.g. Bosetti et al., 2008; Leimbach and Baumstark, 2010; Hübler, 2011). This literature overall finds a significant, but small influence of international technology spillovers on climate policy costs. Yet this literature strand does not specifically deal with trade policy as our analysis does. Notably, a single approach exists that implements the Melitz (2003) mechanism into a numerical general equilibrium model (Balistreri et al., 2011; Balistreri and Rutherford, 2012). This approach captures productivity gains through trade and firm selection, but not technology spillovers through exporting and importing as our approach does. Balistreri et al. 
(2011) find gains from trade liberalization that are four times larger with the Melitz approach than with the standard Armington approach. Balistreri and Rutherford (2012) and Böringer et al. (2012) underline that the Melitz mechanism accentuates the impacts of trade measures (in this case, tariffs based on carbon intensities of products known as border carbon adjustment). Like Balistreri et al. (2011), we build our numerical implementation on theory and an econometric estimation of the parameter values that we require for parameterizing our theoretical approach.

Whereas benchmark year data for the static calibration are available from sources like GTAP 8, parameter values for the dynamic calibration including the international spillover mechanism are not directly available. It is a shortcoming of the literature to apply guesstimated parameter values for the mechanisms of endogenous growth and international technology spillovers. Thus, the main advancement of our implementation compared to the literature is the use of the same mathematical formulation and the same dataset for the model implementation as for the econometric estimation of the model parameter values. The following subsections explain the extended general equilibrium framework and discuss the simulation results.

\subsection{Model setup}

This subsection summarizes the extended model framework. The model is formulated as a Mixed Complementarity Problem (MCP). The details of the mathematical formulation can be found in the Appendix.

We implement Equation (5) from section 2 in combination with the econometric Equation (16). Like in the theoretical basis, we distinguish between period one, short-term, and period two, long-term. We then insert the estimates for the strength of export- and import-induced productivity gains and the rates of exogenous growth from section 3. The resulting CGE model uses the same data as the econometric estimates. We abstain from discounting $(\rho=1)$ in order to keep the results independent of the choice of the discount rate, which would influence the results and which is highly disputed (cf. Gollier and Weitzman, 2010). The stronger the future is discounted, the lower will be the importance of trade-induced productivity gains and hence trade policy.

$$
A^{r s 2}=\left(1+\gamma^{0 r}+\gamma^{M} \frac{M^{r s 1}}{Q^{r s 1}}+\gamma^{E} \frac{E^{r s 1}}{Q^{r s 1}}\right) A^{r s 1}
$$

This specification implies that each sector imports and exports as well, like in the econometric

\footnotetext{
${ }^{8}$ Global Trade Analysis Project, https://www.gtap.agecon.purdue.edu/default.asp.
} 
specification 9 In relation to the econometric specification in Equation (16), $A^{r s}$. corresponds to total factor productivity $\frac{Q^{r s}}{Z^{r s} \text {. }}$. Consequently, the $\gamma$-parameter values are taken from the econometric estimation in the previous section. In the CGE model, it is $A^{r s 0}=\frac{Q^{r s 0}}{Z^{r s 0}}$, where zero indicates the benchmark situation. Output $Q$, imports $M$, exports $E$, and inputs $Z$ are endogenous variables resulting from the general equilibrium in each period, short- and longterm. This means, they can deviate from the benchmark situation. In particular, sectoral shifts $S$, that occur additionally to sector-specific productivity gains $T$, are also captured by the general equilibrium in accordance with Equations (6). In accordance with the econometric specification (16), imports are an (Armington) aggregate of intermediate goods from all sectors and regions (countries) available in this calibration. Exports, on the contrary, encompass only the specific good that a sectors produces and are in general exported to all regions available in this specification. In each sector, imports and exports create sector-specific productivity gains. For computational reasons and for a better regional focus, we aggregate the WIOD dataset to eight regions $r$ : Europe, USA, China, India, Brazil, Russia, East Asia (without China) and Rest of the World. In addition, we aggregate the original 35 WIOD sectors to 18 sector: 10 denoted by $s$. We choose 2007 as the benchmark year representing period 1 . This means, we calibrate our model to the global WIOD input-output table for the year 2007 11 Period 2 is generated by expanding each region and sector according to the above equation.

\subsection{Numerical solution}

This section first and foremost illustrates our theoretical findings for the European economy. It then examines how these results vary across different regions, different benchmark years, different Armington elasticities and thus different degrees of market power, and different European production sectors. It identifies determinants of optimal tariffs and their welfare effects econometrically. It ends with a short resume.

\subsubsection{European trade policy}

In our numerical experiment, we first choose Europe $(E U R)$ in the year 2007 as the exemplary region $r$ in the spotlight. This means, we exogenously vary the tariff $\tau$ imposed on Europe's imports and set equally for all European sectors. We examine the effect of varying the import

\footnotetext{
${ }^{9}$ In the theoretical model we follow the classical trade model type and assume only two sectors which can either be a net importer or a net exporter.

${ }^{10}$ Agriculture/forestry/fishing, chemicals, construction, coke/petroleum/nuclear, electrical/optical equipment, electricity/gas/water supply, food/beverages/tobacco, machinery, metals, mining/quarrying, other nonmetallic minerals, other manufacturing/recycling, paper/printing/publishing, services, transport equipment, textiles, transportation, wood.

${ }^{11}$ We choose 2007 as a compromise between using the newest data and using data that are not affected by the economic crisis. Other benchmark years will be discussed in a robustness check.
} 
tariff on Europe's welfare and identify the optimal tariff with endogenous versus exogenous trade-induced productivity gains for Europe. We also investigate how the other model regions are affected by the European tariff.

We first solve a benchmark run without trade policy intervention. Then, we impose tariffs at various rates on European imports. In the exogenous spillover scenario, denoted by ExoSpill, productivity gains are fixed at their benchmark run values independent of changes in imports and exports. In the endogenous spillover scenario, denoted by EndoSpill, productivity gains are a function of the import and export intensity following our theoretical and empirical model. Importantly, without policy intervention and thus without deviations of the trade pattern, both scenarios generate the same benchmark growth rate between periods one and two. When trade patterns change due to policy intervention, productivity growth will be unaffected in scenario ExoSpill, but will react in scenario EndoSpill. The propositions formulated in the theoretical part basically compare a situation where productivity gains depend on imports and exports with a situation in which they do not. Consequently, the theoretical outcomes can be evaluated by comparing the scenario EndoSpill with ExoSpill.

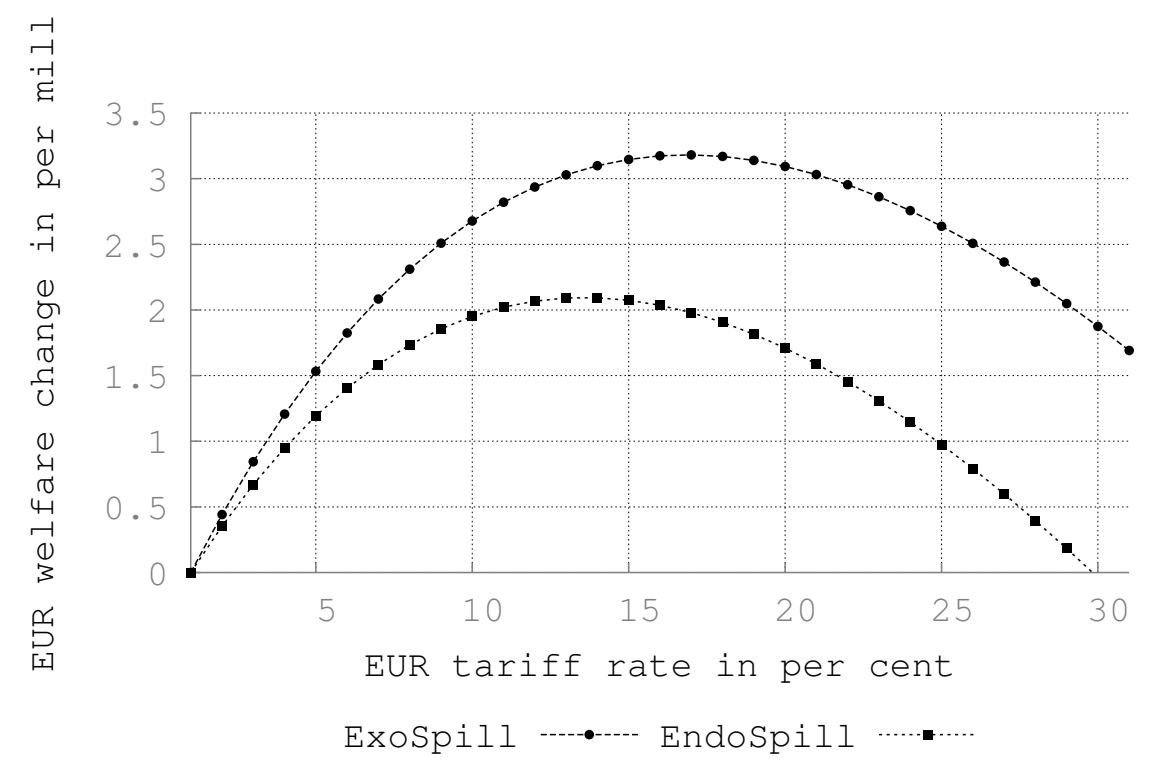

Figure 1: Europe's per mill welfare change in EndoSpill and ExoSpill relative to the benchmark run without a tariff measured within period 2 over various tariff rates.

Figure 1 illustrates Europe's per mill welfare change in EndoSpill and in ExoSpill relative to the benchmark run without a tariff, always measured within period 2 and plotted over various tariff rates. The curve has an inverted U-shape which is typical for optimal tariff analyses.

We recall Proposition 2 stating that productivity gains through imports and exports reduce the optimal tariff manipulating the terms of trade in favor of a large open economy. Figure 1 shows that the optimal, i.e. the welfare-maximizing, tariff rate under EndoSpill is about 13 per 
cent, whereas the optimal tariff rate under ExoSpill is about 16 per cent, which corroborates the proposition.

We recall Proposition 3 stating that there exists a certain strength of productivity gains from trade such that the incentive to manipulate the terms of trade vanishes. In our simulations, the spillover strength of exports and imports is given by the econometric estimates of the previous section. Apparently, the estimated spillover strength is by far too low to completely enervate the incentive to use a tariff for strategic (terms of trade) reasons.

We recall Proposition 4 stating that the welfare gain for a large open economy achieved via a given tariff rate is lower in the presence of productivity gains through imports and exports than in their absence. Figure 1 illustrates that the welfare change curve for EndoSpill always lies below the welfare curve for ExoSpill in accordance with Proposition 2. The maximum welfare gain reached by the optimal tariff is about 3.2 per mill under ExoSpill and only about 2.1 under EndoSpill. This leads us to conclude:

Result 4. The numerical simulations corroborate the relevance and significance of Propositions 2 and 4. Optimal tariffs are always lower when accounting for endogenous productivity growth. For all tariffs welfare is lower if endogenous productivity gains are neglected.

How does the optimal European tariff affect the other regions' welfare? Table 3 answers this question by setting the European tariff to the optimal rate within scenario ExoSpill (16 per cent) and thereafter to the optimal rate within scenario EndoSpill (13 per cent) as depicted by Figure 1. Table 3 reveals the following surprising outcome: the USA gain from Europe's optimal tariff by more than one per mill, whereas the other regions lose to different extents. The USA obviously absorb part of the imports which, previous to the introduction of the optimal tariff, went to Europe and benefit from this inverse trade diversion effect. (Lower European imports attenuate world market prices so that the USA can import at lower prices.) Russia as an energy exporter loses up to 15 per mill, and China up to 9 per mill of welfare due to Europe's tariff. India, on the contrary, is hardly affected by Europe's trade policy. In all cases, the ExoSpill effects with fixed regional productivity growth on the other regions are larger than the EndoSpill effects with endogenous trade-dependent regional growth. The first reason is that the optimal tariff under EndoSpill is lower than under ExoSpill so that the trade impacts are smaller. The second theoretical reason is that Europe can achieve higher productivity growth under EndoSpill. Consequently, it will demand more imports and produce more (or cheaper) exports, which is beneficial for the other regions. Yet it is not beneficial for the USA because they benefit from higher, not from lower European trade barriers due to inverse trade diversion.

With respect to the magnitude of the effects under scrutiny, it turns out that the welfare 
Welfare effects of EU trade policy

$W^{r 2}$

\begin{tabular}{llrr}
\hline & & ExoSpill & EndoSpill \\
& & & \\
European Union & EUR & 3.2 & 2.1 \\
United States of America & USA & 1.5 & 1.1 \\
Russia & $R U S$ & -15.1 & -12.8 \\
Brazil & $B R A$ & -3.6 & -3.2 \\
India & $I N D$ & -0.4 & -0.6 \\
China & $C H N$ & -9.2 & -7.7 \\
East Asia & $E A S$ & -2.6 & -2.1 \\
Rest of the World & $R O W$ & -6.8 & -6.2 \\
& & & \\
\hline
\end{tabular}

Table 3: Regional welfare effects of Europe's optimal tariffs under the scenarios ExoSpill and EndoSpill in period 2 in per mill (compared to the benchmark without tariffs).

changes have a magnitude of some per mill. This means, the effects under scrutiny have a limited economic meaning based on the available data. Notably, our model has only a twoperiod scope. Some per mill of global GDP accumulated over a number of years nonetheless generate a substantial welfare effect. The optimal tariff rates themselves are within a realistic range. For comparison: Europe's unweighed average tariff rate on products from the USA was 7.3 per cent in 2007,12 it reached 9.1 per cent in 1990 and 12.0 per cent in 1995; it declined to 4.6 in 2010. Thus, Europe's computed optimal tariff rates of 13 or 16 per cent are not much above these historical rates.

\subsubsection{Region-specific trade policy}

We carry out the same tariff analysis for the other main model regions, i.e. the United States and the BRIC countries (Brazil, Russia, India and China). Figure 2 in the Appendix puts the European result depicted by Figure 1 in perspective to the corresponding results for the other model regions. Table 4 summarizes the optimal tariffs $\tau_{o p t}^{r}$ and corresponding welfare effects $W^{r 2}$ for the main model regions. The results are reported for each scenario, ExoSpill and EndoSpill (compared to the benchmark without tariffs), and as relative changes of EndoSpill relative to ExoSpill in parentheses.

All optimal tariffs are significantly greater than zero. This outcome is in line with Brown (1987) who argues that in an Armington specification strong terms-of-trade effects exist inde-

\footnotetext{
${ }^{12}$ UNCTAD, TRAINS data, accessed 07/2013.
} 
Region-specific optimal tariffs and welfare effects $\tau_{o p t}^{r}, W^{r 2}$

\begin{tabular}{llrrrrr}
\hline & & & & \\
& & \multicolumn{2}{c}{ ExoSpill } & \multicolumn{2}{c}{ EndoSpill } \\
& & $\tau_{\text {opt }}^{r}$ & $W^{r 2}$ & \multicolumn{2}{c}{$\tau_{\text {opt }}^{r}$} & $W^{r 2}$ \\
European Union & & & & & \\
United States of America & ESA & 16 & 3.2 & $13(-19 \%)$ & $2.1(-34 \%)$ \\
Russia & 24 & 4.8 & $20(-17 \%)$ & $3.6(-25 \%)$ \\
Brazil & RUS & 17 & 3.6 & $13(-24 \%)$ & $2.3(-36 \%)$ \\
India & BRA & 10 & 1.3 & $6(-40 \%)$ & $0.4(-69 \%)$ \\
China & IND & 15 & 4.0 & $11(-27 \%)$ & $2.4(-40 \%)$ \\
& $C H N$ & 18 & 12.1 & $15(-17 \%)$ & $8.8(-27 \%)$ \\
& & & & & & \\
\hline
\end{tabular}

Table 4: Optimal tariffs $\tau_{o p t}^{r}$ of the main model regions in per cent and the corresponding welfare affects $W^{r 2}$ in period 2 in per mill under the scenarios ExoSpill and EndoSpill (compared to the benchmark without tariffs); relative changes of Endospill relative to ExoSpill in per cent in parentheses.

pendent of the size model regions. In our results, the United States' optimal tariffs and welfare gains are higher than Europe's, but their relative changes between ExoSpill and EndoSpill is smaller than for Europe. Russia's optimal values and their changes are slightly higher than Europe's. Brazil's values are relatively small, but the relative change in welfare and the optimal tariff between the scenarios is highest among all regions. India's optimal tariffs are lower than Europe's, yet its welfare gains compared to the baseline are higher; and the relative change in welfare and the optimal tariff between the scenarios is second highest among the regions. Finally, China's optimal tariffs are the highest among the regions, whereas the changes in the optimal tariff and in welfare between ExoSpill and EndoSpill is similar to those of the USA and thus relatively low. Thus, in summary the importance of the optimal tariff with and without productivity spillovers for Europe is lower than for the BRIC countries.

The regional diversity of the results is surprising when considering that we assume the same strength of trade-induced productivity spillovers for all regions (applying the estimated coefficients in Table 1). Thus, country-specific characteristics affect the potential of endogenous trade-induced productivity gains. They are determined by the input-output structure including existing productivity levels, the sectoral composition and trade patterns, and by the exogenous part of the country-specific growth rate as reported by Table 2. In the following subsections we will strive for insights into the drivers of optimal tariffs and their welfare effects. 


\subsubsection{Variation of the benchmark year}

It is a strength of WIOD to offer benchmark data for the years 1995 to 2009. We exploit this strength by calibrating the model to other benchmark years for comparison. Figure 3 in the Appendix shows the outcome for Europe (EUR). Besides the year 2007 (which is also available in the GTAP 13 data), we report results for the year 2004 (which is also available in the GTAP 7 data) and for the most recent available years 2008 and 2009, which goes beyond GTAP. We report the results in parentheses in the form (optimal tariff in per cent/welfare change with respect to benchmark in per mill under ExoSpill — optimal tariff in per cent/welfare change with respect to benchmark in per mill under EndoSpill). In 2004, the optimal tariffs and the corresponding welfare gains for Europe under ExoSpill and EndoSpill (14/2.3 - 11/1.5) are significantly smaller than for 2007 (16/3.2 - 13/2.1). In 2008, the optimal tariffs are the same as in 2007 , whereas the welfare gains are slightly higher $(16 / 3.6-13 / 2.4)$. In 2009 , the values are again smaller $(15 / 2.5-11 / 1.6)$, similar to the result for 2004 . This robustness check demonstrates that the choice of the benchmark year can play a role, i.e. for some years the results are very similar, whereas they differ for some other years. This applies in particular to deviations measured relative to benchmark data, wherein the absolute values of the benchmark data do hardly matter. Nonetheless, different production and trade patterns across benchmark years do matter for the results. We conclude that in general, the sensitivity of the results to the choice of the benchmark year is limited and does not affect the qualitative interpretation of the results. A clear time trend in the benchmark year data is not evident.

\subsubsection{Variation of Armington elasticities}

In another robustness check, we vary the Armington elasticities (the elasticity of substitution between foreign varieties as well as between the import bundle and domestic production taken from GTAP). We refer to Europe calibrated to 2007 data. Higher Armington elasticities make varieties from different countries more similar and reduce market power. Hence, the optimal tariffs and the resulting welfare gains decline in higher Armington elasticities. Figure 2 (e) poses the results for all Armington elasticities set to a high value of 8 , whereas Figure 2 (f) poses the results for all Armington elasticitites set to a low value of 2. In the high Armington case, the optimal tariffs and welfare gains decline substantially to $(10 / 2.6-7 / 1.3)$. In the low Armington case, the values soar to $(63 / 17.6-59 / 15.9)$. We conclude that the sensitivity of the results to the choice of Armington elasticities is high. Moreover, a lower (higher) Armington elasticity represents lower (higher) substitutability between varieties and thus higher (lower)

\footnotetext{
${ }^{13}$ Global Trade analysis Project, https://www.gtap.agecon.purdue.edu/databases/v8/
} 
market power and vice versa. Against this background, the optimal tariffs and corresponding welfare effects rise in market power in accordance with Proposition 1.

Furthermore, we set the Armington elasticities of Europe to a very high value of 2514 This mimics the situation with almost no power on international markets marked by Proposition 1. In accordance with the proposition, we find a negative optimal tariff, i.e. an import subsidy under EndoSpill. The subsidy deteriorates Europe's terms of trade. This result deviates from Brown (1987) who does not take trade-induced productivity gains into account.

Result 5. The numerical simulations corroborate Propositions 1 stating that trade-induced productivity gains can also be exploited without power on international markets to raise welfare, resulting in a negative optimal tariff.

Yet the import subsidy induces productivity gains that overcompensate the deterioration of the terms of trade. The value of the subsidy rate of 1 per cent is small. Likewise, the welfare gain achieved through this optimal subsidy is very small and hence probably negligible by practical trade policy. In accordance with Proposition 1, in this scenario with almost no market power, an export subsidy is detrimental for Europe.

\subsubsection{Sector-specific trade policy}

Finally, we strive for deeper insights into the drivers of the economy-wide effects at the sector level and for insights into competitiveness effects for European sectors. For this purpose, Figure 4 in the Appendix plots forgone total factor productivity (total factor productivity loss) in the policy scenarios with reduced trade compared to the benchmark run. Clearly, reduced trade results in reduced productivity gains. For the time being, we keep the restriction that tariffs are equally chosen for all sectors in the economy. We explore European trade policy, while the other regions do not engage in trade policy. We run scenario EndoSpill twice: once by setting the tariff to its optimal level as before, and once by setting the tariff to the optimal level given by the ExoSpill scenario. We signify the latter setup by EndoSpill - ExoTariff. In EndoSpill-ExoTariff, the tariff is set to a rate above the optimal level. Thus, it generates higher forgone total factor productivity than EndoSpill in all sectors as illustrated in Figure 4. These forgone productivity is solely driven by the trade-induced productivity spillover channel since the tariff rate and all other model parameters are kept constant. Note that the difference in forgone productivity between the two scenarios represents the forgone welfare through not taking into account that trade induces endogenous productivity gains. The figure illustrates that services, construction and electricity/gas/water supply suffer the highest forgone total

\footnotetext{
${ }^{14}$ Perfect substitutes and perfect competition on international markets would require an infinite Armington elasticity, which is not feasible for this type of model.
} 
factor productivity in both scenarios, whereas agriculture/forestry/fishing, mining/quarrying and other non-metallic minerals suffer to the smallest extent. Notably, the economy-wide welfare effect of the trade policies under scrutiny is positive as examined in the previous analysis, because the government collects the revenues from the tariffs and redistributes them to the representative consumer in a lump-sum way and because the tariffs shift demand from imports to domestic supply, which is beneficial for domestic producers. These positive effects overcompensate the forgone sectoral factor productivity (total factor productivity loss) and are not visible in Figure 4.

Now we relax the assumption of an identical tariff on all goods to explore the sectoral dimension in greater detail. A tariff $\tau^{r s}$ specific to sector $s$ is introduced. For each sector $s$, we calculate the optimal tariff $\tau_{\text {opt }}^{E U R}$ that maximizes Europe's welfare $W^{E U R 2}$. Tariffs on all goods except for $s$ are fixed to zero when determining $\tau_{o p t}^{E U R}$.

The results of these simulations are reported by Table 5 in the Appendix. The first column lists the 18 sectors. Columns 2 to 5 display the sectoral optimal tariff $\tau_{\text {opt }}^{E U R}$ in per cent and the corresponding European welfare effects $W^{E U R 2}$ in per mill, both in the ExoSpill and EndoSpill scenario. The percentage changes in parentheses $\left(6^{\text {th }}\right.$ and $7^{\text {th }}$ column) show the differences between the two scenarios in per cent. All further columns display parameters potentially explaining the results. The Armington elasticity between foreign and domestic varieties $\sigma_{s}^{a^{\prime}}$, the import and export intensities, $\frac{M^{E U R s 1}}{Q^{E U R s 1}}$ and $\frac{E^{E U R s 1}}{Q^{E U R s 1}}$, in per cent, the sector size $\frac{Q^{E U R s 1}}{Q^{E U R 1}}$ measured as the share of Europe's total output in per cent, and the share of good $s$ consumed by final demand $\frac{C^{E U R s 1}}{Q^{E U R S 1}}$ in per cent as a measure for the position in the value chain. (A higher final demand share means more downstreamness.)

In general, optimal tariffs and welfare gains are always smaller in the presence of tradeinduced productivity gains 15 This confirms both the theoretical results and the numerical findings for economy-wide optimal tariffs $\tau_{o p t}^{r}$. Sectoral optimal tariffs $\tau_{o p t}^{E U R}$ are generally lower than the economy-wide European tariff, which is $\tau_{o p t}^{E U R}=16$ per cent in the ExoSpill scenario and $\tau_{o p t}^{E U R}=13$ per cent in the EndoSpill scenario. Only the optimal tariff on textiles is greater than $\tau_{o p t}^{E U R}$ in the ExoSpill scenario, while three sectors exhibit optimal tariffs above $\tau_{o p t}^{E U R}$ per cent in the EndoSpill scenario: food, transport equipment and textiles. The largest welfare gain $W^{E U R 2}$ of 0.7 per mill is achieved by the optimal tariff for mining goods. Despite having a high Armington elasticity of about $\sigma_{s}^{a^{\prime}}=8.5$, the mining sector's huge import intensity of 150 per cent allows Europe to exert market power.

The comparison of the chemicals and metals sectors is illuminating. Both account for about 4 per cent of European production. Chemicals, however, exhibit a higher import intensity than

\footnotetext{
${ }^{15}$ The only exception it the optimal tariff on textiles which is identical in both scenarios.
} 
metals, 15 per cent compared to 13 per cent, and a lower Armington elasticity, 3.3 compared to 3.6. Consequently, sectoral optimal tariffs are higher for chemicals, 15 per cent compared to 13 per cent in the ExoSpill and 12 per cent compared to 10 per cent in the EndoSpill scenario. Welfare effects are stronger as well. In the EndoSpill scenario, the welfare gain is 0.19 per mill for chemicals and 0.12 per mill for metals. Without trade-induced productivity gains, expressed by ExoSpill, the welfare gain is 0.29 per mill for chemicals and 0.22 for metals.

Accounting for 53 per cent of total production, the services sector is the largest sector in the European economy. Its Armington elasticity is low $\left(\sigma_{s}^{a^{\prime}}=1.9\right)$. Import intensities are low, too $\left(\frac{M^{s 1}}{Q^{s 1}}=2.5\right.$ per cent). As a consequence, the sectoral optimal tariffs ( 5 per cent under ExoSpill and 2 per cent under EndoSpill) as well as the corresponding welfare effects (0.06 per mill in the ExoSpill and 0.02 per mill in the EndoSpill scenario) are small. Notwithstanding, services is the sector for which neglecting trade-induced productivity gains is most detrimental to Europe's welfare. Considering endogenous trade-induced productivity gains reduces the sectoral optimal tariff by 60 per cent and the welfare gains by 75 per cent. The economic intuition is that a higher sector size implies that any trade-induced productivity gain affects a larger part of the economy and thus has a stronger overall impact on the economy.

Economic intuition is less clear-cut with respect to downstreamness. If trade policy is induced on an upstream sector, its will not only affect this sector, but also consecutive downstream sectors. This mechanism enlarges the impact of productivity gains, but also the welfarereducing distortion induced by tariffs. In order to clarify and quantify the impact of downstreamness as well as import- and export-intensity and sector size on optimal tariffs and welfare gains, we extend the analysis in the following way.

First, we run the sectoral tariff experiment for the year 2007 for all model regions instead for Europe only. In each experiment, one region chooses optimal sectoral tariffs, whereas the remaining regions do not engage in trade policy. As a result, we obtain Table 5 for each model region (not shown). We combine the tables and focus on the scenario EndoSpill that takes the endogeneity of productivity gains into account. We obtain in total 144 observations.

Second, we run regressions with the optimal tariff $\tau_{o p t}^{r s}$ or the resulting second-period welfare gain $W^{r 2}$ as the dependent variable. The explanatory variables are the import and export intensities, $\frac{M^{r s 1}}{Q^{r s 1}}$ and $\frac{E^{r s 1}}{Q^{r s 1}}$, the sector size $\frac{Q^{r s 1}}{Q^{r 1}}$, and the consumption share as a measure for downstreamness $\frac{C^{r s 1}}{Q^{r s 1}}$ as previously defined. The explanatory variables are given by the WIOD data independent of the model setup. All variables are used in natural logarithmic form. Having identified a strong effect of Armington elasticities on optimal tariffs and welfare in the sensitivity analysis, we leave them out in the following regressions because Armington elasticities are not given by primary data, but they are estimated and subject to uncertainty. 
We organize the data in panel form with regions and sectors as the two dimensions. We run an $F$-test that reveals that region-specific fixed-effects are jointly significantly different from zero, but not so sector-specific effects. We run a Hausman test which indicates that random effects would not provide consistent estimates. Therefore, we run a pooled regression and a regression with region-specific fixed-effects with each dependent variable, $\tau_{o p t}^{r s}$ and $W^{r 2}$. In mathematical form we use the following econometric model, in which $\beta$ denotes the coefficients that are estimated:

$$
\begin{aligned}
& \log W^{r 2}=\beta+\beta^{0 r}+\beta^{M} \log \left(\frac{M^{r s 1}}{Q^{r s 1}}\right)+\beta^{E} \log \left(\frac{E^{r s 1}}{Q^{r s 1}}\right)+\beta^{S} \log \left(\frac{Q^{r s 1}}{Q^{r 1}}\right)+\beta^{C} \log \left(\frac{C^{r s 1}}{Q^{r s 1}}\right)+\epsilon^{r s} \\
& \log \tau_{\text {opt }}^{r s}=\beta+\beta^{0 r}+\beta^{M} \log \left(\frac{M^{r s 1}}{Q^{r s 1}}\right)+\beta^{E} \log \left(\frac{E^{r s 1}}{Q^{r s 1}}\right)+\beta^{S} \log \left(\frac{Q^{r s 1}}{Q^{r 1}}\right)+\beta^{C} \log \left(\frac{C^{r s 1}}{Q^{r s 1}}\right)+\epsilon^{r s}
\end{aligned}
$$

Table 6 in the Appendix reports the estimated coefficients and heteroscedasticity robust $p$ values that cluster at the region-level. Whereas the aforementioned $F$-test opts for the use of fixed-effects, the $R^{2}$ values opt for the use of the pooled regression ( 0.47 and 0.77 for pooled versus 0.22 and 0.19 for fixed-effects). The $F$-tests for the null hypothesis of all coefficients being not significantly different from zero show higher $F$-values in the fixed-effects than in the pooled regressions. The import intensity has a highly significant and positive coefficient in the first three regressions. The coefficient has a higher magnitude for the welfare effect than for the optimal tariff. The export intensity has a significant and positive coefficient in the first two regressions, but a weakly significant negative coefficient with a small magnitude in the fourth regression. A larger sector share has a positive, though weakly significant impact on welfare. Its impact on the optimal tariff is not significant. A larger consumption share and hence downstreamness significantly increase the optimal tariff , but not welfare. The coefficient without fixed-effects is an order of magnitude higher than with fixed-effects. In summary, the positive coefficients of import and export intensity, the sector and the consumption share are in accordance with economic intuition. In accordance with our estimates presented in Table 1 , the import intensity appears to play the dominant role in trade policy that aims at welfare maximization.

\subsubsection{Summary and discussion of the numerical analysis}

We can summarize the numerical results in general form as follows:

Result 6. A constant given magnitude of trade-induced productivity gains exhibits regionally and sectorally diverse optimal tariffs and induced welfare effects. Lower Armington elasticities (lower substitution possibilities between traded goods), higher import or export intensities as well as higher sector or consumption shares raise the optimal tariff and its welfare effects. 
This heterogeneity across regions and sectors computed within a complex multi-region, multi-sector general equilibrium framework extends the pure trade-induced effect found in our simplified theoretical model in Equation (14) and Result (3). Trade policy that aims at welfare maximization needs to take this heterogeneity into account.

The variation of the benchmark year has a small impact on the results - at least when measuring deviations between the policy scenario and the benchmark scenario in relative from - whereas the choice of Armington elasticities has a strong impact.

In relation to the literature, our results are in line with studies that examine the influence of international technology spillovers on climate policy costs (e.g. Bosetti et al., 2008; Leimbach and Baumstark, 2010; Hübler, 2011). These studies find a significant, but small influence. Like in Balistreri et al. (2011), the welfare effects of tariff variations appear small in our analysis. The endogeneity of trade-induced productivity gains does, however, not as strongly affect the results as in Balistreri et al.'s explicit Melitz implementation. Though, their analysis is not directly comparable to our's since it does not examine optimal tariffs imposed by one region. Compared to the optimal tariff analysis by Ossa (2011) that neglects international productivity gains, we find lower optimal tariffs and lower welfare gains. For the EU without retaliation and without lobbying, for example, Ossa finds an optimal tariff of over 60 per cent and a welfare gain of almost two per cent. We find an optimal tariff of 16 per cent and a resulting welfare gain for the EU of about three per mill (0.3 per cent) without endogenous productivity gains. Our results are closer to those by Markusen and Wigle (1989). They find an optimal tariff for the USA of about 18 percent in a multi-region Nash equilibrium, while we find an optimal tariff for the USA of 20 per cent with endogenous productivity gains, but without a Nash game. Notably, we use a stylized two-period setup. Running the model over a long time horizon would result in a higher cumulated welfare gain. Rutherford and Tarr (2002) simulate a 54-year time horizon. Consequently, they find an average welfare gain of ten per cent induced by a ten per cent tariff cut, which appears huge compared to the trade-induced welfare gains of some per mill found in our analysis.

\section{Conclusion}

Our research explores how endogenous productivity gains from trade affect tariff instruments imposed by a large open economy. It builds on a threefold methodological basis and has direct policy implications. It evidences that trade-induced productivity gains exist which counteract strategic trade policy and which are policy relevant. Our results caution against the strategic use of tariffs in order to manipulate the terms of trade. Instead, they opt for reducing trade 
barriers, for example in a European Union- United States free trade agreement, to exploit productivity growth induced by the international exchange of goods and services.

Markusen (1975) models an environmental externality occurring in the foreign country. The home country requires market power in order to influence international prices and thus to have an impact on the externality abroad. This means, the model requires the large open economy assumption. This is different in our model. The productivity (technology) spillover externality occurs in the home country. Therefore, the home country has an incentive to enhance trade in order to magnify the externality even in the absence of power on international markets. Trade-induced productivity spillovers also differ from the standard terms-of-trade effect, which disappears in the absence of market power. The mechanism scrutinized in our model works under the large open economy as well as the small open economy assumption.

We estimate the parameters governing the strength of trade-induced productivity spillovers by applying panel data econometrics. We employ the same dataset that we use to calibrate the general equilibrium model in the subsequent step. The results show that imports imply higher productivity gains than exports. The parameter relating import intensity to productivity growth is more than twice as big as the parameter for export intensity. Based on our stylized theoretical model, the optimal tariff is reduced by 5 per cent when taking the endogeneity of trade-induced productivity gains into account.

Our numerical simulations embed the stylized theoretical approach into a more complex and realistic computable general equilibrium (CGE) model. Whereas all qualitative results from the theoretical model are confirmed by the simulations, quantitative effects differ strongly between regions and sectors. Trade-induced productivity gains are more important for trade policies of the BRIC countries, especially Brazil and India, than of Europe or the USA. Nevertheless, trade-induced productivity gains provide an argument for the reduction of trade barriers such as in the transatlantic free trade agreement. Notably, the European optimal tariff implies welfare gains for the USA, presumably through trade diversion effects. This finding counteracts expected benefits from a transatlantic free trade agreement to some extent. Neglecting the endogeneity of trade-induced productivity gains creates welfare losses. The welfare effects, however, have a small magnitude at the macroeconomic level. Welfare gains from enhanced trade become particularly small when the home country's power on international markets is negligible. Trade-induced productivity gains increase in existing market power. Notably, our analysis does not accumulate growth effects over a long time horizon. Over a long time horizon the trade-induced productivity effects will become larger.

Sectoral optimal tariffs and their sensitivity with respect to trade-induced productivity gains are diverse and have sometimes high magnitudes. Hence, trade policy may focus on 
specific sectors. In larger sectors, downstream sectors as well as import- or export-intensive sectors trade policy can generate stronger welfare gains.

Our robustness checks reveal a limited effect of choosing different benchmark years for the model calibration on the results. The reason is that policy impacts are commonly measured as relative deviations from the benchmark year so that the size of the benchmark year economy is of limited importance. Elasticities of substitution between foreign varieties as well as foreign and domestic varieties (Armington elasticities) have a strong impact on the results because they determine the degree of market power a country exhibits. Every trade policy analysis carried out with the standard Armington mechanism hinges upon these elasticities.

Future research could extent the number of simulation steps over time and the time frame of the simulations in order to scrutinize scenarios of long-term growth.

\section{References}

Ackerman, F. and Gallagher, K.P. (2008). The shrinking gains from global trade liberalization in computable general equilibrium models - a critical assessment. International Journal of Political Economy 37(1), 50-77.

Antras, P., Chor, D., Fally, T. and Hillberry, R.H. (2012). Measuring the Upstreamness of Production and Trade Flows. American Economic Review: Papers \&3 Proceedings 102(3), 412-416.

Armington, P. (1969). A theory of demand for products distinguished by place of production. IMF Staff Papers, Washington, DC, USA 16, 159-178.

Balistreri, E.J., Hillberry, R.H. and Rutherford, T.F. (2011). Structural estimation and solution of international trade models with heterogeneous firms. Journal of International Economics 83, 95-108.

Balistreri, E.J. and Rutherford, T.F. (2012). Subglobal carbon policy and the competitive selection of heterogeneous firms. Energy Economics 34, Supplement 2, 190-197.

Böhringer, C., Balistreri, E.J. and Rutherford, T.F. (2012). The role of border carbon adjustment in unilateral climate policy: Overview of an Energy Modeling Forum study (EMF 29). Energy Economics 34, Supplement 2, 97-110.

Bosetti, V., Carraro, C., Massetti, E. and Tavoni, M. (2008). International energy R\&D spillovers and the economics of greenhouse gas atmospheric stabilization. Energy Economics 30(6), 2912-2929.

Broda, C., Limao, N. and Weinstein, D.E. (2008). Optimal Tariffs and Market Power: The Evidence. American Economic Review 98(5), 2032-2065.

Brown, D.K. (1987). Tariffs, the terms of trade, and national product differentiation. Journal of Policy Modeling 9, 503-526.

Coe, D. and Helpman, E. (1995). International R\&D Spillovers. European Economic Review $39,859-887$. 
Coe, D., Helpman, E. and Hoffmaister, A. (1997). North-South R\&D Spillover. The Economic Journal 107, 134-149.

Diao, X., Rattsø, J. and Stokke, H.E. (2005). International spillovers, productivity growth and openness in Thailand: An intertemporal general equilibrium analysis. Journal of Development Economics 76, 429-50.

Dietzenbacher, E., Los, B., Stehrer, R., Timmer, M. and de Vries, G. (2013). The Construction of World Input-Output Tables in the WIOD Project. Economic Systems Research 25(1), 71-98.

Felbermayr, G., Jung, B. and Larch, M. (2013).Optimal tariffs, retaliation, and the welfare loss from tariff wars in the Melitz model. Journal of International Economics 89(1), 1325.

Girma, S., Greenaway, D. and Kneller, R. (2004). Does Exporting Increase Productivity? A Microeconometric Analysis of Matched Firms. Review of International Economics 12(5), 855-866.

Gollier, C. and M.L. Weitzman (2010). How should the distant future be discounted when discount rates are uncertain? Economics Letters 107, 350-353.

Gros, D. (1987). A note on the optimal tariff, retaliation and the welfare loss from tariff wars in a framework with intra-industry trade. Journal of International Economics 23(3-4), 357-367.

Grossman, E. and Helpman, E. (1991).Trade, knowledge spillovers, and growth. European Economic Review 35(2-3), 517-526.

Hamilton, B. and Whalley, J. (1983). Optimal Tariff Calculations in Alternative Trade Models and Some Possible Implications for Current World Trading Arrangements. Journal of International Economics 15, 323-348.

Havranek, T. and Irsova, Z. (2011). Estimating vertical spillovers from FDI: Why results vary and what the true effect is. Journal of International Economics 85, 234-244.

Helpman, E. and Krugman, P. (1989). Trade Policy and Market Structure. MIT Press, Cambridge, MA.

Hübler, M. (2011). Technology diffusion under contraction and convergence: a CGE analysis of China. Energy Economics 33 (1), 131-142.

Hübler, M. and Keller, A. (2009). Energy Savings via FDI? Empirical Evidence from Developing Countries. Environment and Development Economics 15(1), 59-80.

Jakob, M., Marschinski, R. and Hübler, M. (2013). Between a Rock and a Hard Place: A Trade-Theory Analysis of Leakage under Production- and Consumption-Based Policies. Environmental and Resource Economics 56(1), 47-72.

Johnson, H.G. (1954). Optimum Tariffs and Retaliation. Review of Economic Studies 21(2), 142-153.

Keller, W. (2004). International technology diffusion. Journal of Economic Literature 42(3), 752-782.

Kennan, J. and Riezman, R. (1988). Do Big Countries Win Tariff Wars? Canadian Journal of Economics 23(1), 70-83.

Kennan, J. and Riezman, R. (1990). Optimal Tariff Equilibria with Customs Unions. International Economic Review 29(1), 81-85. 
Koesler, S. and Schymura, M. (2014). Substitution Elasticities in a Constant Elasticity of Substitution Framework - Empirical Estimates Using Non-Linear Least Squares. Economic Systems Research, forthcoming.

Krugman, P. (1980). Scale Economies, Product Differentiation, and the Pattern of Trade. American Economic Review 70(5), 950-959.

Leimbach, M. and Baumstark, L. (2010). The impact of capital trade and technological spillovers on climate policies. Ecological Economics 69, 2341-2355.

Markusen, J.R. (1975). International externalities and optimal tax structures. Journal of International Economics 5, 15-29.

Markusen, J.R and R.M. Wigle (1989). Nash Equilibrium Tariffs for the United States and Canada: The Roles of Country Size, Scale Economies, and Capital Mobility. Journal of Political Economy 97(2), 368-386.

Mayer, W. (1984). Endogenous Tariff Formation. American Economic Review 74(5), 970-985.

Melitz, M.J. (2003). The Impact of Trade on Intra-Industry Reallocations and Aggregate Industry Productivity. Econometrica 71(6), 1695-1725.

Ossa, R. (2011). Trade Wars and Trade Talks with Data. NBER Working Paper 17347, Cambridge, MA, USA.

Rutherford, T.F. and Tarr, D.G. (2002). Trade liberalization, product variety and growth in a small open economy: a quantitative assessment. Journal of International Economics 56, $247-272$.

Saggi, K. (2002). Trade, foreign direct investment, and international technology transfer: a survey. The World Bank Research Observer 17(2), 191-235. 


\section{Supplementary Appendix}

\subsection{Mathematical formulation of the numerical model}

The general equilibrium model is written in price or marginal-cost form as a mixed complementarity problem (MCP). It consists of the following elements:

\section{Zero-profit conditions:}

First, the main production function, defined over all regions and sectors, generates (final) goods by using production factors and (intermediate) goods as inputs:

$$
0 \geq \pi_{r s t}^{Q}=p_{r s t}^{Q}-C E S_{r s t}^{\sigma^{k l e m}}\left\{p_{r s t}^{m}, C E S_{r s t}^{\sigma^{k l e}}\left[C E S_{r t}^{\sigma^{k l}}\left(p_{r t}^{l}, p_{r t}^{k}\right), C E S_{r s t}^{\sigma^{e}}\left(p_{r s t}^{e}\right)\right]\right\}
$$

where $\pi$ denotes profits, $p$ a price (not a price ratio) and $C E S$ a constant elasticity of substitution function with the arguments in parentheses and the elasticity of substitution $\sigma$ in the upper index. As before, $r$ denotes regions, $s$ sectors and $t$ time (years). $Q$ denotes a produced quantity. $k$ signifies capital, $l$ labor, $e$ energy and $m$ non-energy (intermediate) goods. These are inputs written in small letters. The above inequality implies perfect competition on goods markets. Goods are traded between regions, whereas the production factors capital and labor are region-specific, but perfectly mobile across sectors within regions. Like in the econometric analysis, the elasticities of substitution are taken from Koesler and Schymura (2014) who estimate them with the help of the same WIOD dataset. We will apply alternative upper and lower bound Armington elasticities in a robustness check.

Second, the Armington (1969) trade structure, indicated by a and defined over source and recipient regions and sectors, aggregates a good produced in various foreign regions to a bundle and combines it with the corresponding domestically produced good thereafter.

$$
0 \geq \pi_{r s t}^{a}=p_{r s t}^{a}-C E S_{r s t}^{\sigma_{s}^{a^{\prime}}}\left[p_{r s t}^{q}, C E S_{r^{*} s t}^{\sigma_{s}^{a}}\left(p_{r^{*} s t}^{q}-\tau_{r s}\right)\right]
$$

where $r^{*}$ signifies source regions, whereas $r$ denotes recipient regions. The index em denotes that both, non-energy and energy goods, are included. This condition implies that no profits exist within the Armington trade domain. Nonetheless, goods produced in different regions are not perfect substitutes; they are distinct varieties. The preference for each variety is determined by its share in total imports given by the benchmark data. The sensitivity of this share with respect to (price) shocks is determined by the Armington elasticity of substitution which is sector-specific. $\sigma_{s}^{a}$ symbolizes the elasticity of substitution between imported varieties from

different regions, whereas $\sigma_{s}^{a^{\prime}}$ symbolizes the elasticity of substitution between the bundle of 
imported varieties and the domestically produced variety. As a consequence of the Armington specification, each region has some extent of (monopolistic) market power on international goods markets. Since the WIOD data do not contain parameter values for the Armington elasticities, we borrow them from the GTAP 16 data. Armington trade has implications for optimal trade policy. Notably, product differentiation by country of origin implies some degree of market power for all regions (cf. Brown, 1987).

$\tau$ is the ad valorem import tariff rate that we will exogenously vary in our numerical simulations. In the first step we will assume the same tariff rate for all goods imported to country $r$. In the second step we will differentiate $\tau$ by country $r$ and sector $s$.

Third, the consumption function, defined over regions, aggregates non-energy goods to a bundle and energy goods to another bundle and combines them thereafter:

$$
0 \geq \pi_{r t}^{c}=p_{r t}^{c}-C E S_{r t}^{\sigma^{c m e}}\left[C E S_{r s t}^{\sigma^{c m}}\left(p_{r s t}^{m}\right), C E S_{r s t}^{\sigma^{c e}}\left(p_{r s t}^{e}\right)\right]
$$

This function defines the representative consumer of each region.

\section{Market clearance conditions:}

First, domestic production must satisfy domestic input demand, Armington export demand and domestic consumption so that all goods markets clear:

$$
Q_{r s t} \geq \sum_{s^{\prime}} \frac{\partial \pi_{r s^{\prime} t}^{q}}{\partial p_{r s t}^{q}} Q_{r s^{\prime} t}+\sum_{r^{*}} \frac{\partial \pi_{r^{*} s t}^{e m}}{\partial p_{r s t}^{q}} M_{r^{*} s t}+\frac{\partial \pi_{r t}^{c}}{\partial p_{r s t}^{q}} C_{r t}
$$

where $Q$ denotes the output value, $M$ the import value and $C$ consumption as before. $s^{\prime}$ signifies sectors that demand good $s$ as an intermediate input $\left(s^{\prime}\right.$ and $s$ cover the same set of sectors so that a specific sector can also receive intermediate inputs from itself), and $r^{*}$ again foreign regions.

Second, domestic import demand for each good must absorb the supply of this good by all foreign regions so that all international goods markets clear:

$$
M_{r s t} \geq \sum_{r^{*}} \frac{\partial \pi_{r^{*} s t}^{e m}}{\partial p_{r s t}^{e m}} Q_{r^{*} s t}
$$

Third, an intratemporal condition ensures that the representative consumer of each region spends his budget fully on consumption:

$$
C_{r t} \geq \frac{B_{r t}}{p_{r t}^{c}}
$$

\footnotetext{
${ }^{16}$ Global Trade Analysis Project, https://www.gtap.agecon.purdue.edu/
} 
where $B$ denotes the value of the consumer's budget.

\section{Budget condition:}

The model is closed by imposing a balanced budget condition on each representative consumer:

$$
B_{r t}=p_{r t}^{l} \bar{L}_{r t}+p_{r}^{k} \bar{K}_{r}+\bar{p}^{d} \bar{D}_{r}
$$

where $\bar{L}$ and $\bar{K}$ characterize the consumer's endowments with labor and capital. $\bar{D}$ indicates a fixed current account deficit (given by the data) associated with the numeraire price $\bar{p}^{d}=1$.

\subsection{Supplementary figures and tables}




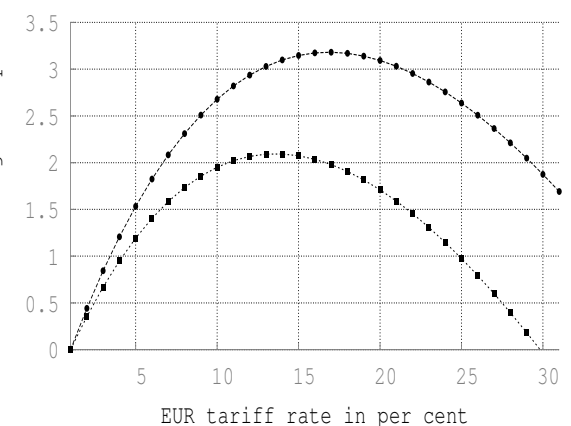

(a)

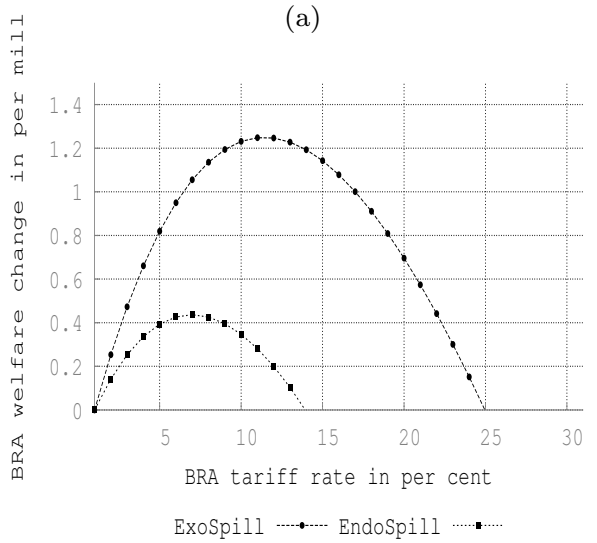

(c)

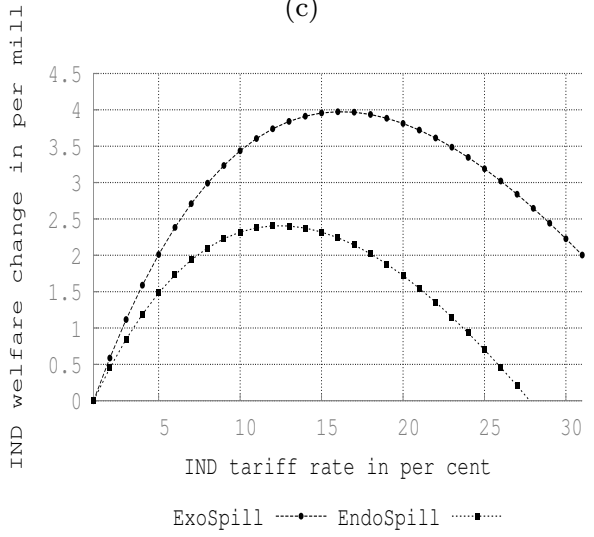

(e)

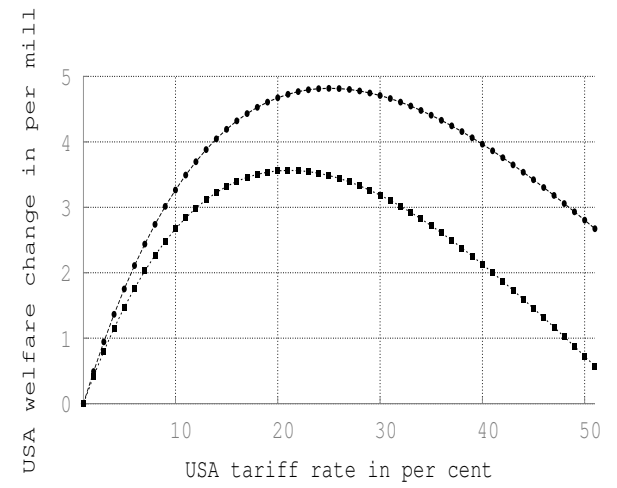

ExoSpill …...... EndoSpill …..

(b)

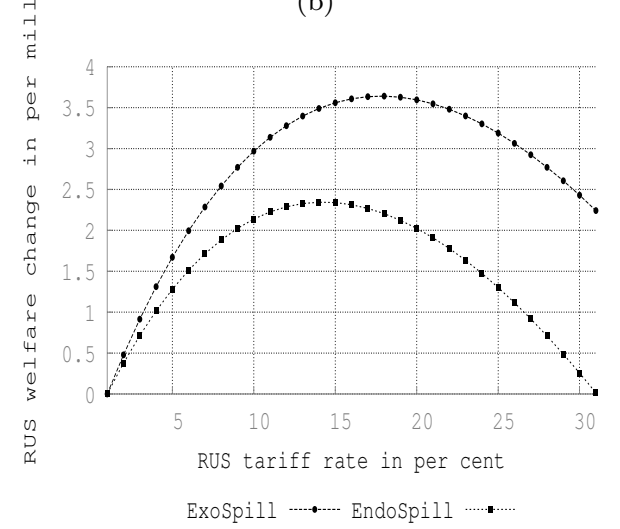

(d)
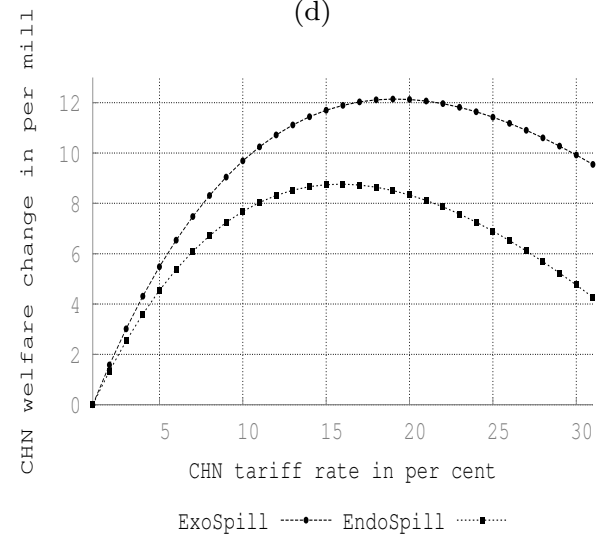

(f)

Figure 2: Regional per mill welfare changes in EndoSpill and ExoSpill relative to the benchmark run without a tariff measured within period 2 over various tariff rates; note different scales of the vertical axes and for the USA the scale of the horizontal axis; the depicted regions are (a) Europe, (b) USA, (c) Brazil, (d) Russia, (e) India, (f) China; the benchmark year is always 2007. 


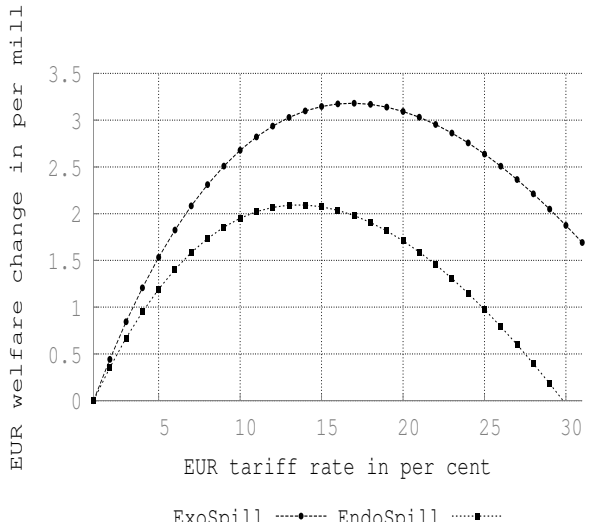

(a)

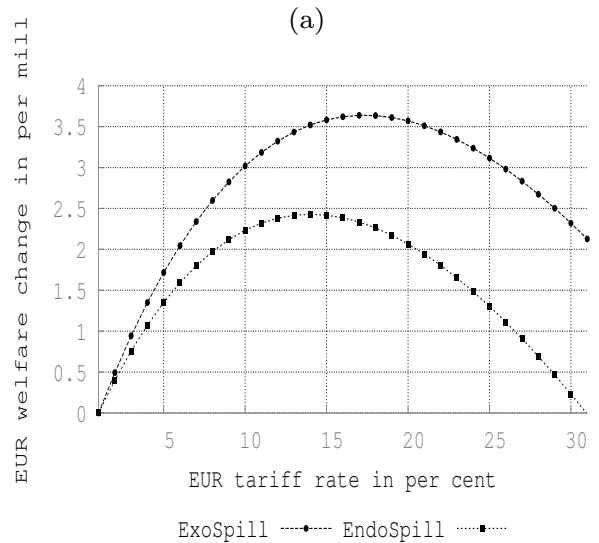

(c)

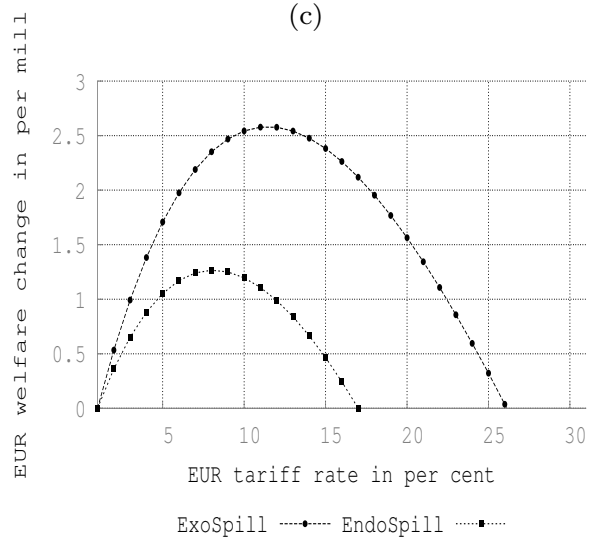

(e)

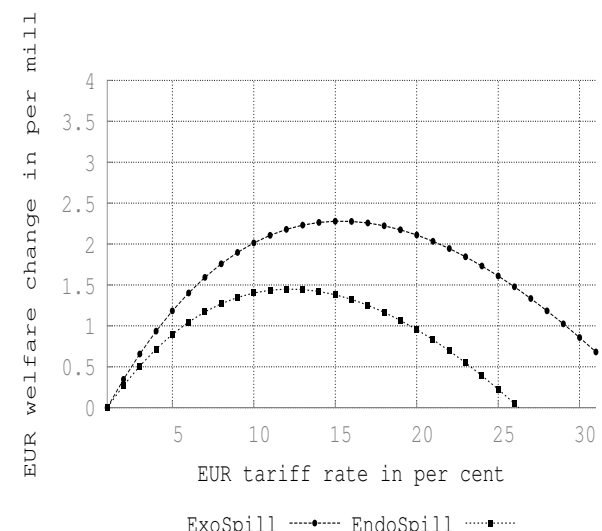

(b)

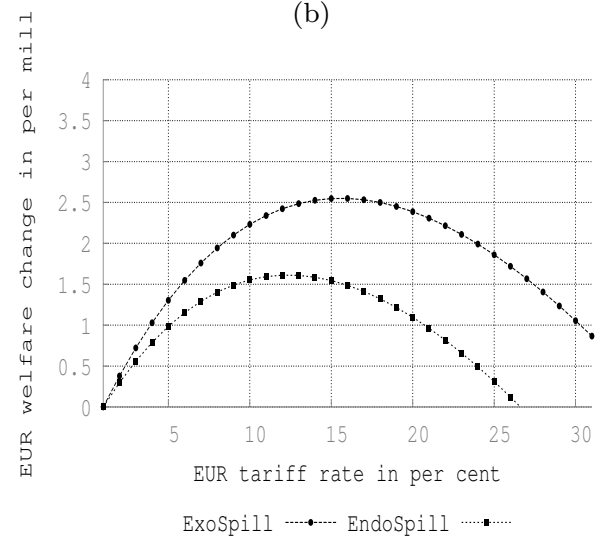

(d)
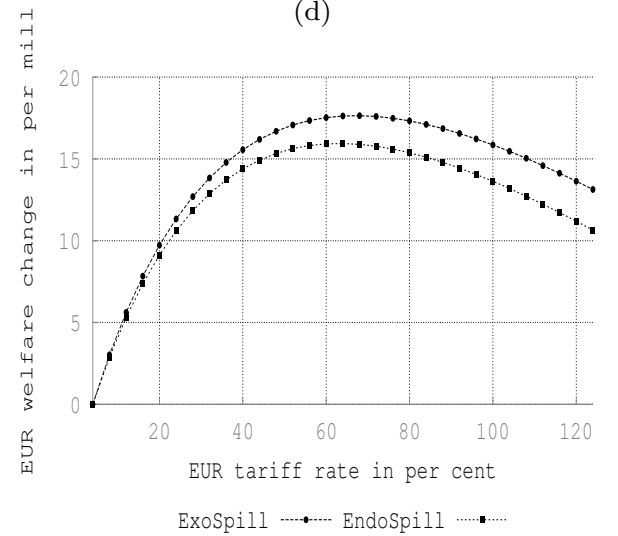

(f)

Figure 3: European per mill welfare change in EndoSpill and ExoSpill relative to the benchmark run without a tariff measured within period 2 over various tariff rates; the different benchmark years are (a) 2007, (b) 2004, (c) 2008, (d) 2009, (e) 2007 with all Armington elasticities set to 8, (f) 2007 with all Armington elasticities set to 2 . 


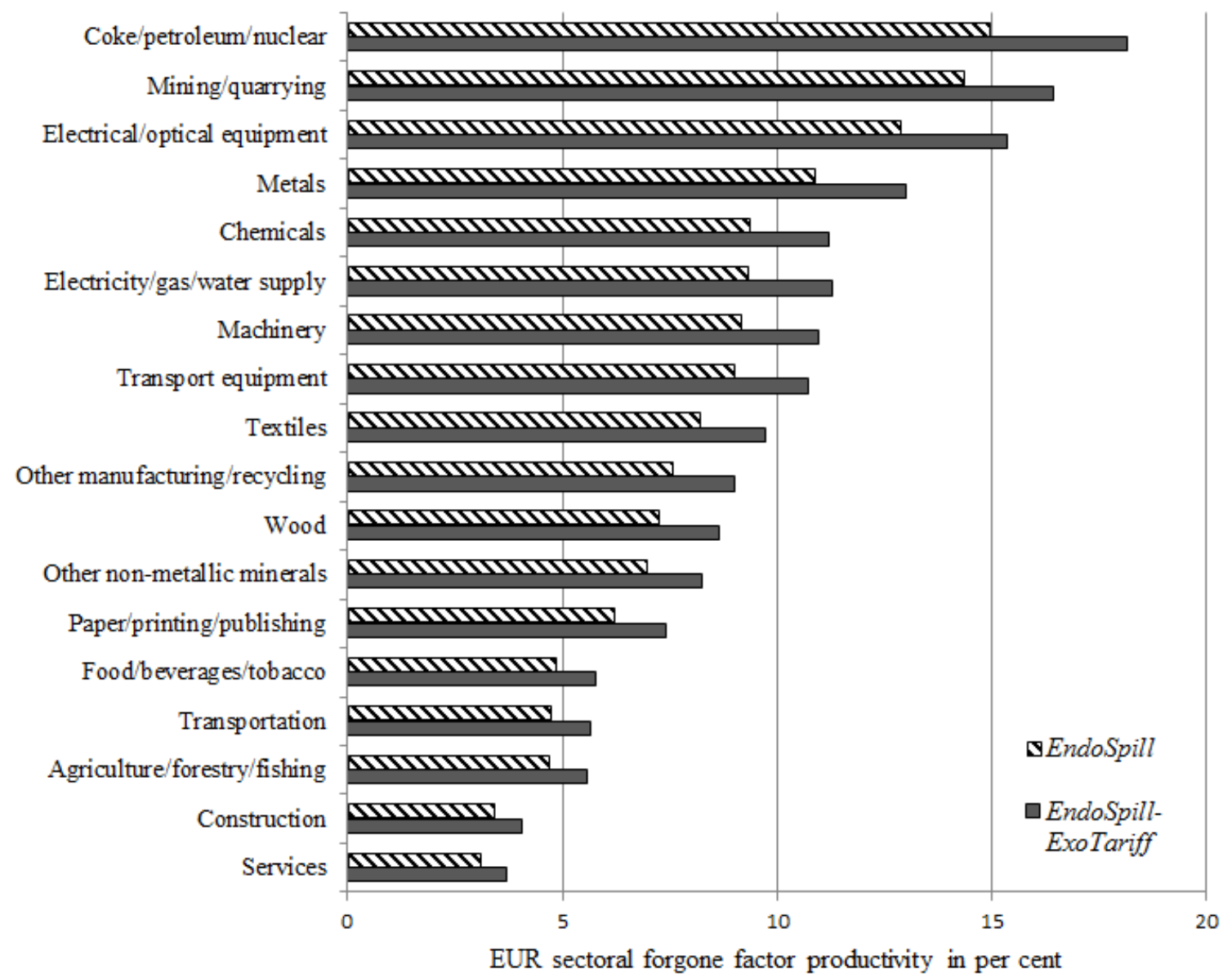

Figure 4: Forgone total factor productivity through tariffs in European sectors in per cent under EndoSpill and EndoSpill - ExoTariff relative to the benchmark run without a tariff measured within period 2. EndoSpill applies the optimal tariff in the presence of endogenous spillovers, whereas EndoSpill-ExoTariff applies the optimal tariff of the ExoSpill scenario to the EndoSpill scenario. 
Sector-specific optimal tariffs and welfare effects $\tau_{\text {opt }}^{E U R}, W^{E U R 2}$

\begin{tabular}{|c|c|c|c|c|c|c|c|c|c|c|c|}
\hline \multirow[b]{2}{*}{ Sector } & \multicolumn{2}{|c|}{$\begin{array}{c}\text { ExoSpill } \\
\text { tariff \& welf. }\end{array}$} & \multicolumn{4}{|c|}{$\begin{array}{l}\text { EndoSpill } \\
\text { tariff \& welf. }\end{array}$} & \multirow{2}{*}{$\begin{array}{c}\text { Armin. } \\
\text { elas. } \\
\qquad \sigma_{s}^{a^{\prime}}\end{array}$} & \multirow{2}{*}{$\begin{array}{l}\text { Import } \\
\text { intensity } \\
\frac{M^{E U R s 1}}{Q^{E U R s 1}}\end{array}$} & \multirow{2}{*}{$\begin{array}{r}\text { Export } \\
\text { intensity } \\
\frac{E^{E U R s 1}}{Q^{E U R s 1}}\end{array}$} & \multirow{2}{*}{$\begin{array}{l}\text { Sector } \\
\text { share } \\
\frac{Q^{E U R s 1}}{Q^{E U R 1}}\end{array}$} & \multirow{2}{*}{$\begin{array}{l}\text { Consum. } \\
\text { share } \\
\frac{C^{E U R s 1}}{Q^{E U R s 1}}\end{array}$} \\
\hline & $\tau_{o p t}^{E U R s}$ & $W^{E U R 2}$ & $\tau_{o p t}^{E U R s}$ & & $W^{E U R 2}$ & & & & & & \\
\hline Agriculture & 14 & 0.09 & 13 & $(-7 \%)$ & 0.07 & $(-22 \%)$ & 2.93 & 9.6 & 2.8 & 1.9 & 39.8 \\
\hline Mining & 15 & 0.71 & 12 & $(-20 \%)$ & 0.47 & $(-35 \%)$ & 8.48 & 150.1 & 7.2 & 0.7 & 8.7 \\
\hline Minerals & 11 & 0.01 & 8 & $(-27 \%)$ & 0.01 & $(-47 \%)$ & 1.90 & 4.8 & 9.0 & 1.0 & 12.9 \\
\hline Food & 16 & 0.15 & 15 & $(-6 \%)$ & 0.14 & $(-9 \%)$ & 2.91 & 7.2 & 1.6 & 3.8 & 63.9 \\
\hline Wood & 13 & 0.02 & 10 & $(-23 \%)$ & 0.01 & $(-41 \%)$ & 3.40 & 6.8 & 8.7 & 0.6 & 15.0 \\
\hline Paper & 11 & 0.03 & 8 & $(-27 \%)$ & 0.01 & $(-47 \%)$ & 2.95 & 4.4 & 8.4 & 1.8 & 27.9 \\
\hline Coke & 14 & 0.08 & 11 & $(-21 \%)$ & 0.06 & $(-31 \%)$ & 2.10 & 17.1 & 11.1 & 1.6 & 37.9 \\
\hline Chemicals & 15 & 0.29 & 12 & $(-20 \%)$ & 0.19 & $(-33 \%)$ & 3.30 & 15.0 & 15.4 & 4.0 & 30.6 \\
\hline Metals & 13 & 0.22 & 10 & $(-23 \%)$ & 0.12 & $(-48 \%)$ & 3.63 & 13.0 & 12.7 & 3.9 & 13.2 \\
\hline Trans. equip. & 16 & 0.29 & 15 & $(-6 \%)$ & 0.24 & $(-18 \%)$ & 3.55 & 11.5 & 10.2 & 4.0 & 55.0 \\
\hline Elec. equip. & 13 & 0.32 & 10 & $(-23 \%)$ & 0.20 & $(-37 \%)$ & 4.40 & 28.3 & 15.8 & 3.0 & 40.0 \\
\hline Textiles & 17 & 0.22 & 17 & $(0 \%)$ & 0.20 & $(-8 \%)$ & 3.83 & 35.1 & 4.8 & 1.1 & 64.0 \\
\hline Transport & 12 & 0.08 & 10 & $(-17 \%)$ & 0.05 & $(-39 \%)$ & 1.90 & 7.0 & 10.3 & 5.4 & 28.4 \\
\hline Machinery & 12 & 0.15 & 11 & $(-8 \%)$ & 0.12 & $(-22 \%)$ & 4.05 & 11.7 & 14.0 & 2.8 & 51.8 \\
\hline Other manu. & 14 & 0.08 & 13 & $(-7 \%)$ & 0.07 & $(-9 \%)$ & 3.75 & 14.4 & 5.6 & 1.0 & 60.8 \\
\hline Electricity & 15 & 0.02 & 13 & $(-13 \%)$ & 0.01 & $(-32 \%)$ & 2.80 & 1.2 & 0.9 & 2.8 & 34.3 \\
\hline Construction & 8 & 0.00 & 6 & $(-25 \%)$ & 0.00 & $(-33 \%)$ & 1.90 & 0.3 & 0.3 & 7.7 & 67.2 \\
\hline Services & 5 & 0.06 & 2 & $(-60 \%)$ & 0.02 & $(-75 \%)$ & 1.90 & 2.5 & 2.3 & 53.0 & 56.2 \\
\hline
\end{tabular}

Table 5: Optimal sectoral tariffs $\tau_{o p t}^{E U R s}$ in EUR in per cent and the corresponding welfare affects $W^{E U R 2}$ in period 2 in per mill under the scenarios ExoSpill and EndoSpill (compared to the benchmark without tariffs); changes of Endospill relative to ExoSpill in per cent in parentheses; sectoral import shares $\frac{M^{E U R S}}{Q^{E U R S 1}}$ and export shares $\frac{E^{E U R s 1}}{Q^{E U R S 1}}$ for the EU in per cent as well as sectoral output share $\frac{Q^{E U R s 1}}{Q^{E U R 1}}$ in the EU economy in per cent; commodity share consumed by final demand $\frac{C^{E U R s 1}}{Q^{E U R s 1}}$ in total demand (including intermediate goods demand) in per cent; sector names in short form, for more details see Figure 4 and footnote 8 . 


\begin{tabular}{|c|c|c|c|c|c|}
\hline & & $\begin{array}{l}\text { We } \\
\log W^{r 2}\end{array}$ & $\begin{array}{c}\text { are gains an } \\
\qquad(2) \\
\log \tau_{o p t}^{r s}\end{array}$ & $\begin{array}{l}\text { optimal t } \\
\qquad(3) \\
\log W^{r 2}\end{array}$ & $\begin{array}{l}\text { riffs } \\
\qquad \begin{array}{l}(4) \\
\log \tau_{o p t}^{r s}\end{array}\end{array}$ \\
\hline Constant & & & & $\begin{array}{l}0.019 \\
(0.58)\end{array}$ & $\begin{array}{c}0.11^{* * *} \\
(5.8 \mathrm{e}-07)\end{array}$ \\
\hline Import intensity & $\frac{M^{r s 1}}{Q^{r s 1}}$ & $\begin{array}{c}0.35^{* * *} \\
(4.8 \mathrm{e}-06)\end{array}$ & $\begin{array}{c}0.056^{* * *} \\
(0.000045)\end{array}$ & $\begin{array}{l}0.34^{* * *} \\
(0.0021)\end{array}$ & $\begin{array}{l}0.011 \\
(0.15)\end{array}$ \\
\hline Export intensity & $\frac{E^{r s 1}}{Q^{r s 1}}$ & $\begin{array}{l}0.46^{* *} \\
(0.023)\end{array}$ & $\begin{array}{c}0.29 * * * \\
(7.1 \mathrm{e}-07)\end{array}$ & $\begin{array}{c}0.31 \\
(0.23)\end{array}$ & $\begin{array}{c}-0.073^{*} \\
(0.088)\end{array}$ \\
\hline Sector share & $\frac{Q^{r s 1}}{Q^{r 1}}$ & $\begin{array}{c}0.85^{*} \\
(0.062)\end{array}$ & $\begin{array}{l}0.017 \\
(0.82)\end{array}$ & $\begin{array}{c}0.76 \\
(0.16)\end{array}$ & $\begin{array}{r}-0.093 \\
(0.15)\end{array}$ \\
\hline Consum. share & $\frac{C^{r s 1}}{Q^{r s 1}}$ & $\begin{array}{l}0.074 \\
(0.17)\end{array}$ & $\begin{array}{c}0.22^{* * *} \\
(0)\end{array}$ & $\begin{array}{c}0.089^{*} \\
(0.098)\end{array}$ & $\begin{array}{c}0.051^{* *} \\
(0.018)\end{array}$ \\
\hline$F$ & & $\begin{array}{c}7.36 \\
(0.0000)\end{array}$ & $\begin{array}{c}2.50 \\
(0.0452)\end{array}$ & $\begin{array}{c}27.81 \\
(0.0002)\end{array}$ & $\begin{array}{c}31.12 \\
(0.0002)\end{array}$ \\
\hline $\begin{array}{l}\text { Adj. } R^{2} \\
\text { Number of observ. } \\
\text { Region fixed-effects }\end{array}$ & & $\begin{array}{c}0.470 \\
144\end{array}$ & $\begin{array}{c}0.766 \\
144\end{array}$ & $\begin{array}{c}0.224 \\
144 \\
\text { yes }\end{array}$ & $\begin{array}{c}0.188 \\
144 \\
\text { yes }\end{array}$ \\
\hline
\end{tabular}

Robust $p$-values in parentheses

$* * * \mathrm{p}<0.01, * * \mathrm{p}<0.05,{ }^{*} \mathrm{p}<0.1$

Table 6: Panel estimation for 8 regions and 18 sectors for the year 2007 based on scenario EndoSpill, pooled and region-specific fixed-effects. 